\title{
Nitrosamine exposure exacerbates high fat diet-mediated type 2 diabetes mellitus, non-alcoholic steatohepatitis, and neurodegeneration with cognitive impairment Suzanne M de la Monte*1,2,3,4,5, Ming Tong 3,5 , Margot Lawton ${ }^{3}$ and Lisa Longato Li, $^{3,4}$
}

Address: ${ }^{1}$ Department of Pathology (Neuropathology), Rhode Island Hospital, 593 Eddy Street, Providence, RI 02903 USA, ${ }^{2}$ Department of Neurology, Rhode Island Hospital, 593 Eddy Street, Providence, RI 02903 USA, ${ }^{3}$ Liver Research Center, Rhode Island Hospital, 55 Claverick Street, Providence, RI 02903 USA, ${ }^{4}$ Pathobiology Program, Brown University, Box G, 222 Richmond Street, Providence, RI 02903 USA and ${ }^{5}$ Warren Alpert Medical School of Brown University, Box G, 97 Waterman Street, Providence, RI 02912 USA

Email: Suzanne M de la Monte* - Suzanne_DeLaMonte_MD@Brown.edu; Ming Tong - ming_tong_ming@yahoo.com;

Margot Lawton - mlawton425@gmail.commail.com; Lisa Longato - Lisa_Longato@Brown.edu

* Corresponding author

Published: 24 December 2009

Molecular Neurodegeneration 2009, 4:54 doi:10.1186/1750-1326-4-54
Received: 15 October 2009

Accepted: 24 December 2009

This article is available from: http://www.molecularneurodegeneration.com/content/4/I/54

(C) 2009 de la Monte et al; licensee BioMed Central Ltd.

This is an Open Access article distributed under the terms of the Creative Commons Attribution License (http://creativecommons.org/licenses/by/2.0), which permits unrestricted use, distribution, and reproduction in any medium, provided the original work is properly cited.

\begin{abstract}
Background: The current epidemics of type 2 diabetes mellitus (T2DM), non-alcoholic steatohepatitis (NASH), and Alzheimer's disease (AD) all represent insulin-resistance diseases. Previous studies linked insulin resistance diseases to high fat diets or exposure to streptozotocin, a nitrosamine-related compound that causes T2DM, NASH, and AD-type neurodegeneration. We hypothesize that low-level exposure to nitrosamines that are widely present in processed foods, amplifies the deleterious effects of high fat intake in promoting T2DM, NASH, and neurodegeneration.
\end{abstract}

Methods: Long Evans rat pups were treated with N-nitrosodiethylamine (NDEA) by i.p. Injection, and upon weaning, they were fed with high fat (60\%; HFD) or low fat (5\%; LFD) chow for 6 weeks. Rats were evaluated for cognitive impairment, insulin resistance, and neurodegeneration using behavioral, biochemical, molecular, and histological methods.

Results: NDEA and HFD \pm NDEA caused T2DM, NASH, deficits in spatial learning, and neurodegeneration with hepatic and brain insulin and/or IGF resistance, and reductions in tau and choline acetyltransferase levels in the temporal lobe. In addition, pro-ceramide genes, which promote insulin resistance, were increased in livers and brains of rats exposed to NDEA, HFD, or both. In nearly all assays, the adverse effects of HFD+NDEA were worse than either treatment alone.

Conclusions: Environmental and food contaminant exposures to low, sub-mutagenic levels of nitrosamines, together with chronic HFD feeding, function synergistically to promote major insulin resistance diseases including T2DM, NASH, and AD-type neurodegeneration. Steps to minimize human exposure to nitrosamines and consumption of high-fat content foods are needed to quell these costly and devastating epidemics. 


\section{Background}

Alzheimer's Disease (AD), obesity, type 2 diabetes mellitus (T2DM), and non-alcoholic fatty liver disease (NAFLD)/non-alcoholic steatohepatitis (NASH), which includes metabolic syndrome, have sharply increased in prevalence over the past several decades [1-6]. In addition, we have noted striking increases in age-specific AD mortality rates over the same time interval, and correlated these findings with sharply increased consumption of processed foods, use of preservatives, and demand for nitrogen-containing fertilizers [7]. Such rapid shifts in age-adjusted AD morbidity and mortality are more consistent with exposure-related rather than genetic etiologies. A common theme resonating from these lifestyle trends is that we have increased our exposures to nitrosamines ( $\mathrm{R} 1 \mathrm{~N}(-\mathrm{R} 2)-\mathrm{N}=\mathrm{O})$ and related compounds.

Nitrosamines form by chemical reactions between nitrites and secondary amines or proteins, and they exert toxic or mutagenic effects by promoting DNA damage, oxidative stress and reactive oxygen species generation [8]. The end result is increased lipid peroxidation, adduct formation, and pro-inflammatory cytokine activation [9], which also happen to be major mediators of human insulin-resistance diseases, including T2DM, NASH, and AD [10-16]. The notion that chronic injury caused by alkylating agents could lead to malignant transformation and/or tissue degeneration is consistent with the findings that: 1) chronic exposure to tobacco nitrosamines causes both lung cancer and emphysema with chronic obstructive pulmonary disease; and 2) treatment with streptozotocin (STZ), a nitrosamine-related compound, causes hepatocellular carcinoma, pancreatic carcinoma, malignant brain tumors, T2DM, neurodegeneration, and/or hepatic steatosis, depending on dose and route of administration [17-25]. Therefore, better characterization of the non-neoplastic and degenerative effects of nitrosamines is warranted.

STZ, like other N-nitroso compounds, functions as: 1) an alkylating agent and potent mutagen [17]; 2) an inducer of DNA adducts leading to apoptosis [26]; 3) a mediator of unscheduled DNA synthesis, triggering cell death [17]; 4) an inducer of single-strand DNA breaks and stimulus for nitric oxide (NO) formation following breakdown of its nitrosamine group [19]; and 5) an enhancer of the xanthine oxidase system leading to increased production of superoxide anion, $\mathrm{H}_{2} \mathrm{O}_{2}$, and $\mathrm{OH}^{-}$radicals [27]. Ultimately, STZ-induced injury and DNA damage promote mitochondrial dysfunction [19], ATP deficits [28], and cell death. The structural similarities between STZ and nitrosamines, including N-nitrosodiethylamine (NDEA) and N-nitrosodimethylamine (NDMA) [29], together with experimental evidence that high doses of STZ cause cancer while lower doses cause diabetes or AD-type neurodegen- eration with cognitive impairment $[18,19,25]$, led us to hypothesize that while high doses of nitrosamine exposures cause cancer, lower, sub-mutagenic doses may promote insulin resistance-mediated degenerative diseases.

There is growing evidence that obesity, T2DM, and cognitive impairment are inter-related based on findings that: 1) the risk of developing mild cognitive impairment (MCI), dementia, or AD is increased in individuals with T2DM [10,30] or obesity/dyslipidemic disorders [31]; 2) brain insulin resistance and insulin deficiency progress with severity of AD [32-35]; 3) experimental models of T2DM and/or obesity exhibit MCI [36,37] and neurodegeneration with brain insulin resistance $[38,39]$; 4) experimentally induced brain insulin resistance and insulin deficiency cause AD-type neurodegeneration and cognitive impairment $[24,25,40-42]$; 5) insulin sensitizer agents or intranasal insulin [43-49] can improve cognitive performance in experimental models of $\mathrm{AD}$ [22] or in humans with $\mathrm{AD}$ or $\mathrm{MCI}$; and 6) similar molecular, biochemical, and mechanistic abnormalities in T2DM, NASH, and AD [10-14,16,50]. However, chronic high fat diet (HFD)-induced obesity that leads to NASH and T2DM is not sufficient to cause AD; instead, the associated neurodegeneration is relatively mild, despite brain insulin resistance [38,39]. Correspondingly, most individuals with T2DM do not develop AD, and the vast majority of individuals with AD are neither obese nor diabetic. Therefore, some additional co-factors must determine who among the at-risk population will likely develop AD. Herein, we examined the hypothesis that early sub-mutagenic exposure to NDEA and chronic HFD feeding additively or synergistically mediate the triad of major insulin resistances diseases, including T2DM, NASH, and AD-type neurodegeneration with cognitive impairment.

\section{Materials and methods Materials}

Chow high fat (D12492-60\% of calories) and low fat (D12450B-10\% of calories) diets were commercially prepared by Research Diets, Inc. (New Brunswick, NJ). Rabbit, mouse, or goat generated monoclonal or polyclonal antibodies to ubiquitin, tau, phospho-tau (AT8-S199, S202, T205), glial fibrillary acidic protein (GFAP), 4hydroxy-2-nonenal (HNE), choline acetyltransferase (ChAT), amyloid precursor protein amyloid- $\beta$ peptide (A $\beta$ PP-A $\beta$ ), $\beta$-actin, were purchased from Chemicon (Tecumsula, CA), CalBiochem (Carlsbad, CA), or Molecular Probes (Eugene, OR). All other polyclonal and monoclonal antibodies and immunodetection reagents were purchased from Abcam (Cambridge, MA), Vector Laboratories (Burlingame, CA), Upstate (Billerica, MA), Chemicon (Temecula, CA), or Molecular Probes (Eugene, OR). The insulin ultra-sensitive ELISA kit was obtained from ALPCO Diagnostics (Salem, NH). Histochoice fixative 
was purchased from Amresco, Inc (Solon, OH). Infinity Alanine aminotransaminase (ALT/GPT) assay kits were purchased from Fisher Diagnostics (Middletown, VA). Antibodies to tumor necrosis factor- $\alpha$ (TNF- $\alpha$ ) and interleukin-1 $\beta$ (IL-1 $\beta$ ) were purchased from Invitrogen (Carlsbad, CA). Antibodies to Akt, phospho-Akt (Thr308), GSK3 $\beta$, and phospho-GSK-3 $\beta$ (Ser9) were purchased from Cell Signaling (Danvers, MA). The Amplex Red Cholesterol Assay Kit and Amplex UltraRed soluble fluorophore were purchased from Invitrogen (Carlsbad, CA). MaxiSorb 96-well plates used for ELISAs were from Nunc (Thermo Fisher Scientific; Rochester, NY). The TopCount NXT and ATP Lite assay kit were from Perkin-Elmer (Waltham, MA). Superblock-TBS, horseradish peroxidase conjugated antibodies, and SuperSignal Enhanced Chemiluminescence Reagent were from Pierce Chemical Co (Rockford, IL). QIAzol Lysis Reagent for RNA extraction and QuantiTect SYBR Green PCR Mix were obtained from Qiagen, Inc (Valencia, CA). The AMV $1^{\text {st }}$ Strand cDNA Synthesis kit was purchased from Roche Applied Science (Indianapolis, IN). [125I]-Labeled recombinant insulin and IGF-I polypeptides were purchased from GE Healthcare (Picataway, NJ), and unlabeled recombinant insulin and IGF-1 polypeptides were purchased from Bachem Americas, Inc. (Torrance, CA). The Serum Triglyceride Determination kit and synthetic oligonucleotides used in quantitative polymerase chain reaction (qPCR) assays were purchased from Sigma-Aldrich Co (St. Louis, $\mathrm{MO}$ ). Fine chemicals were purchased from CalBiochem (Carlsbad, CA) or Sigma-Aldrich (St. Louis, MO).

\section{Experimental Model}

Postnatal day 3 (P3) Long Evans rat pups (mean body weight $10 \mathrm{~g}$ ) were given 3 alternate day intra-peritoneal (i.p.) injections of $20 \mu \mathrm{g}$ NDEA or vehicle. Upon weaning, rats ( $\mathrm{N}=8-10$ per group) were pair-fed for 6 weeks with high fat (HFD) or low fat (LFD) chow diets. The HFD supplied $60 \%$ of the kcal in fat (54\% from lard, $6 \%$ from soybean oil), 20\% in carbohydrates, and $20 \%$ in protein, whereas the LFD supplied $10 \%$ of the kcal in fat $(4.4 \%$ from lard, $5.6 \%$ from soybean oil), $70 \%$ in carbohydrates, and $20 \%$ in protein. The use of young rats enabled us to compare results with previous observations in the STZ model [51]. Moreover, longitudinal studies of nuns revealed that neuro-cognitive deficits precede the onset of dementia by decades $[52,53]$, suggesting that early life exposures may contribute to the pathogenesis of $\mathrm{AD}$.

Rats were weighed weekly, and food consumption was monitored daily. At the end of the feeding period, the rats were then subjected to Morris Water Maze testing of spatial learning and memory $[22,25]$. Then, after an overnight fast (14 hours), rats were sacrificed by i.p. injection of pentobarbital $(120 \mathrm{mg} / \mathrm{kg})$, and blood, pancreas, liver, and brain (temporal lobes) were harvested. Blood or serum was used to measure glucose, insulin, cholesterol, triglyceride, free fatty acid, and alanine transaminase (ALT) as previously described $[38,39]$. The tissues were used for histological, biochemical, and molecular studies.

For histological studies, tissues were immersion fixed in Histochoice, embedded in paraffin, and sections $(5-\mu \mathrm{m}$ thick) were stained with Hematoxylin and Eosin (H\&Eliver and pancreas) or Luxol fast blue, H\&E (temporal lobes) and examined under code. For molecular and biochemical studies, liver and temporal lobe samples were snap-frozen in a dry ice-methanol bath and stored at $80^{\circ} \mathrm{C}[22,25,38,39]$. The temporal lobes were studied because they: 1) require intact insulin/IGF signaling mechanisms to maintain structural and functional integrity $[51,54]$; 2) are severely damaged by i.c.-STZ mediated neurodegeneration [22,25]; and 3) are major targets of neurodegeneration in $\mathrm{AD}$ [51]. Our experimental protocol was approved by the Institutional Animal Care and Use Committee at Lifespan-Rhode Island Hospital, and conforms to the guidelines set by the National Institutes of Health.

\section{Morris Water Maze Testing}

Morris Water Maze testing [55] of spatial learning and memory was performed on 4 consecutive days as previously described $[22,25]$. On the first day of testing, the rats were oriented to the water maze and educated about the location of the platform. On the 3 subsequent days of testing, the platform was submerged just below the surface, and rats were tested for learning and memory by measuring the latency period required to reach and recognize the platform. The rats were placed in the same quadrant of the water maze for every trial on Days 1 and 2, but on days 3 and 4 , the start locations were randomized. Data from all 3 trials on each day were used to calculate latency area under the curve. Inter-group comparisons were made using the Kruskal-Wallis one-way ANOVA and Dunn's multiple comparison post-hoc test of significance.

\section{Lipid Assays}

Lipid analyses were performed with serum samples and chloroform-methanol (2:1) extracted fresh frozen liver tissue homogenates [38]. Total lipid content was measured using a Nile Red fluorescence-based assay [56-58], and fluorescence intensity (Ex 485/Em 572) was measured in a SpectraMax M5 microplate reader (Molecular Devices Corp., Sunnyvale, CA). Triglycerides, cholesterol, and free fatty acids were measured with commercially available assay kits.

\section{Quantitative Reverse Transcriptase Polymerase Chain Reaction (qRT-PCR) Assays of Gene Expression}

Total RNA was reverse transcribed with random primers, and the CDNA templates were PCR amplified with gene 
specific primer pairs [25] (Table 1). The amplified products were detected and analyzed in triplicate using the Mastercycler ep realplex instrument and software (Eppendorf AG, Hamburg, Germany) [38,59]. Relative mRNA abundance was calculated from the ng ratios of mRNA to $18 \mathrm{~S}$ rRNA measured in the same samples, and those data were used for inter-group comparisons. Control studies included analysis of: 1) template-free reactions; 2) RNA that had not been reverse transcribed; 3) RNA samples pre-treated with DNAse I; 4) samples treated with RNAse A prior to the reverse transcriptase reaction; and 5) genomic DNA. All assays were performed in triplicate.

\section{Enzyme-Linked Immunosorbant Assay (ELISA)}

Tissues were homogenized in radioimmunoprecipitation assay buffer containing protease and phosphatase inhibitors [39]. Direct ELISAs were performed in 96-well Maxisorb plates [60]. In brief, proteins $(40 \mathrm{ng} / 100 \mu \mathrm{l})$ adsorbed to well bottoms by over night incubation at $4{ }^{\circ} \mathrm{C}$, were blocked with $1 \%$ BSA in phosphate buffered saline (PBS), and then incubated with primary antibody $(0.2-1.0 \mu \mathrm{g} / \mathrm{ml})$ for 1 hour at $37^{\circ} \mathrm{C}$. Immunoreactivity was detected with horseradish peroxidase (HRP)-conjugated secondary antibody (1:10000) and UltraRed soluble fluorophore [60].

For capture ELISAs used to measure pro-inflammatory cytokines, capture antibodies $(1 \mu \mathrm{g} / \mathrm{ml})$ were adsorbed to the well bottoms overnight, and after blocking for 3 hours at room temperature with $1 \%$ BSA prepared in PBS + $0.05 \%$ Tween-20, $50 \mathrm{ng}$ of liver homogenate protein were added to each well in a $100 \mu$ l volume, and incubated for 2 hours at room temperature. Reactions were then incubated with biotinylated detection antibodies $(0.2 \mu \mathrm{g} / \mathrm{ml}$ for IL- $1 \beta$ and TNF $\alpha$, and $0.5 \mu \mathrm{g} / \mathrm{ml}$ for IL-6) for $2 \mathrm{hrs}$ at room temperature. Immunoreactivity was revealed with HRP-conjugated Streptavidin and Amplex UltraRed. Fluorescence was measured (Ex 568/Em 581) in a SpectraMax M5 microplate reader. Binding specificity was determined from parallel negative control incubations with the primary or secondary antibody omitted. Immunoreactivity was normalized to protein content in parallel wells as determined with the NanoOrange Protein Quantification Kit.

\section{Receptor Binding Assays}

Competitive equilibrium binding studies were used to measure effects of NDEA and HFD feeding on insulin and IGF-I receptor binding in liver and temporal lobe [39,61]. For total binding, NP-40 lysis buffer homogenates were incubated with $50 \mathrm{nCi} / \mathrm{ml}$ of [125I] $(2000 \mathrm{Ci} / \mathrm{mmol} ; 50$ pM) insulin or IGF-I in binding buffer (100 mM HEPES (4-(2-hydroxyethyl)-1-piperazine-ethanesulfonic acid), $\mathrm{pH} 8.0,118 \mathrm{mM} \mathrm{NaCl}, 1.2 \mathrm{mM} \mathrm{MgSO} 4,8.8 \mathrm{mM}$ dextrose, $5 \mathrm{mM} \mathrm{KCl}, 1 \%$ bovine serum albumin). For non-specific binding, identical reactions were prepared with the addition of $0.1 \mu \mathrm{M}$ unlabeled (cold) ligand. After 16-hours incubation at $4^{\circ} \mathrm{C}$, reactions were vacuum harvested (Corning, Lowell, MA) onto 96-well GF/C filter plates that were pre-soaked in $0.33 \%$ polyethyleneimine. The filters were vacuum washed with $50 \mathrm{mM}$ HEPES, $\mathrm{pH} 7.4,500$ $\mathrm{mM} \mathrm{NaCl}$, and $0.1 \%$ BSA. [125I]- bound insulin or IGF-I was measured in a TopCount. Specific binding was calculated by subtracting non-specifically bound from the total bound isotope [39].

\section{Statistical Analysis}

Data depicted in the graphs and tables represent the means \pm S.E.M.'s for 8-10 samples per group. Inter-group comparisons were made using two-way ANOVA and posthoc Bonferroni's multiple comparison test of significance. Statistical analyses were performed using the GraphPad Prism 5 software (GraphPad Software, Inc., San Diego, $\mathrm{CA})$. Significant P-values are shown in the graphs or included in the tables.

\section{Results \\ Effects of NDEA and HFD on Serum Biomarkers of T2DM, Dyslipidemia, Body Weight, and Brain Weight}

Fasting blood glucose and serum insulin concentrations were significantly higher in NDEA-treated rats, with or without HFD-feeding, relative to LFD fed, vehicle treated controls, and the highest mean blood glucose and serum insulin levels were detected in the HFD+NDEA group (Figs 1A-B). Serum neutral lipid (Nile Red assay) (Fig. 1C), cholesterol (Fig. 1D), triglyceride (Fig. 1E), and free fatty acid (Fig. 1F) levels were either unchanged or significantly reduced in the NDEA, HFD, and HFD+NDEA treated groups relative to control, and the lowest mean serum lipid levels were measured in the HFD \pm NDEA treated groups. Therefore, hyperglycemia and hyperinsulinemia were features of chronic HFD feeding, and these indices of peripheral insulin resistance were worsened by prior exposure to low-dose NDEA. In addition, early NDEA exposure alone was sufficient to cause mild but significant peripheral insulin resistance. In contrast, neither the NDEA exposure nor the chronic HFD feeding caused hyperlipidemia, indicating that seemingly favorable serum lipid profiles can exist in the context of peripheral insulin resistance or T2DM. These findings are similar to those in a previous report in which the experimental model was generated with much higher doses of NDEA than used herein [62]. One possible interpretation of these seemingly paradoxical results is that homeostasis may have shifted toward increased storage of lipids/triglycerides in adipose tissue, skeletal muscle, and/or liver. Although initial mean body weights were similar among the groups (data not shown), at the time of sacrifice, HFD \pm NDEA treated rats were significantly heavier than LFD \pm NDEA treated rats (Fig. 1G). The mean brain weights did 
Table I: Primer Pairs Used for Quantitative Reverse Transcriptase Polymerase Chain Reaction Assays

\begin{tabular}{|c|c|c|c|c|}
\hline Primer & Direction & Sequence $\left(5^{\prime} \rightarrow 3^{\prime}\right)$ & Position (mRNA) & Amplicon Size (bp) \\
\hline Insulin & For & TTC TAC ACA CCC AAG TCC CGT C & 145 & 135 \\
\hline Insulin & $\operatorname{Rev}$ & ATC CAC AAT GCC ACG CTT CTG C & 279 & \\
\hline Insulin Receptor & For & TGA CAA TGA GGA ATG TGG GGA C & 875 & 129 \\
\hline Insulin Receptor & $\operatorname{Rev}$ & GGG CAA ACT TTC TGA CAA TGA CTG & 1003 & \\
\hline IGF-I & For & GAC CAA GGG GCT TTT ACT TCA AC & 65 & 127 \\
\hline IGF-I & $\operatorname{Rev}$ & TTT GTA GGC TTC AGC GGA GCA C & 191 & \\
\hline IGF-I Receptor & For & GAA GTC TGC GGT GGT GAT AAA GG & 2138 & 113 \\
\hline IGF-I Receptor & Rev & TCT GGG CAC AAA GAT GGA GTT G & 2250 & \\
\hline IGF-II & For & CCA AGA AGA AAG GAA GGG GAC C & 763 & 95 \\
\hline IGF-II & $\operatorname{Rev}$ & GGC GGC TAT TGT TGT TCA CAG C & 857 & \\
\hline IGF-II Receptor & For & TTG CTA TTG ACC TTA GTC CCT TGG & 1066 & 91 \\
\hline IGF-II Receptor & $\operatorname{Rev}$ & AGA GTG AGA CCT TTG TGT CCC CAC & 1156 & \\
\hline IRS-I & For & GAT ACC GAT GGC TTC TCA GAC G & 604 & 134 \\
\hline IRS-I & $\operatorname{Rev}$ & TCG TTC TCA TAA TAC TCC AGG CG & 737 & \\
\hline IRS-2 & For & CAA CAT TGA CTT TGG TGA AGG GG & 255 & 109 \\
\hline IRS-2 & $\operatorname{Rev}$ & TGA AGC AGG ACT ACT GGC TGA GAG & 263 & \\
\hline IRS-4 & For & ACC TGA AGA TAA GGG GTC GTC TGC & 2409 & 132 \\
\hline IRS-4 & $\operatorname{Rev}$ & TGT GTG GGG TTT AGT GGT CTG G & 2540 & \\
\hline ChAT & For & TCA CAG ATG CGT TTC ACA ACT ACC & 478 & 106 \\
\hline ChAT & Rev & TGG GAC ACA ACA GCA ACC TTG & 583 & \\
\hline AChE & For & TTC TCC CAC ACC TGT СCT CAT C & 420 & 123 \\
\hline $\mathrm{AChE}$ & $\operatorname{Rev}$ & TTC ATA GAT ACC AAC ACG GTT CCC & 542 & \\
\hline APP & For & GCA GAA TGG AAA ATG GGA GTC AG & 278 & 199 \\
\hline APP & $\operatorname{Rev}$ & AAT CAC GAT GTG GGT GTG CGT C & 476 & \\
\hline Tau & For & CGC CAG GAG TTT GAC ACA ATG & 244 & 65 \\
\hline Tau & Rev & CCT TCT TGG TCT TGG AGC ATA GTG & 308 & \\
\hline SPTLC-I & For & CTAACCTTGGGCAAATCGAA & 2581 & 96 \\
\hline SPTLC-I & $\operatorname{Rev}$ & TGAGCAGGGAGAAGGGACTA & 2676 & \\
\hline
\end{tabular}


Table I: Primer Pairs Used for Quantitative Reverse Transcriptase Polymerase Chain Reaction Assays (Continued)

\begin{tabular}{|c|c|c|c|c|}
\hline SPTLC-2 & For & GGA CAG TGT GTG GCC TTT CT & 1823 & 50 \\
\hline SPTLC-2 & $\operatorname{Rev}$ & TCA CTG AAG TGT GGC TCC TG & 1872 & \\
\hline CERS-I & For & TGC GTG AAC TGG AAG ACT TG & 947 & 98 \\
\hline CERS-I & $\operatorname{Rev}$ & CTT CAC CAG GCC ATT ССT TA & 1044 & \\
\hline CERS-2 & For & CTC TGC TTC TCC TGG TTT GC & 698 & 82 \\
\hline CERS-2 & $\operatorname{Rev}$ & CCA GCA GGT AGT CGG AAG AG & 779 & \\
\hline CERS-4 & For & CGA GGC AGT TTC TGA AGG TC & 1240 & 72 \\
\hline CERS-4 & Rev & CCA TTG GTA ATG GCT GCT CT & $|3| 1$ & \\
\hline CERS-5 & For & GAC AGT CCC ATC CTC TGC AT & 1254 & 92 \\
\hline CERS-5 & $\operatorname{Rev}$ & GAG GTT GTT CGT GTG TGT GG & 1345 & \\
\hline UGCG & For & GAT GCT TGC TGT TCA CTC CA & 2682 & 67 \\
\hline UGCG & $\operatorname{Rev}$ & GCT GAG ATG GAA GCC ATA GG & 2748 & \\
\hline SMPD-I & For & CAG TTC TTT GGC CAC ACT CA & 1443 & 65 \\
\hline SMPD-I & $\operatorname{Rev}$ & CGG CTC AGA GTT TCC TCA TC & 1507 & \\
\hline SMPD-3 & For & TCT GCT GCC AAT GTT GTC TC & 2704 & 98 \\
\hline SMPD-3 & $\operatorname{Rev}$ & CCG AGC AAG GAG TCT AGG TG & 2801 & \\
\hline
\end{tabular}

*Abbreviations: IGF = insulin-like growth factor; IRS = insulin receptor substrate; ChAT = choline acetyltransferase; $\mathrm{AChE}=$ acetylcholinesterase; APP = amyloid precursor protein; SPTLC = serine palmitoyltransferase; CERS = ceramide synthase; UGCG = UDP-glucose ceramide glucosyltransferase; SMPD = sphingomyelin phosphodiesterase; bp = base pair.

not differ significantly among the groups (Fig. 1H), but the brain/body weight ratios were significantly reduced in $\mathrm{HFD} \pm$ NDEA relative to the LFD \pm NDEA treated rats (Fig. $1 \mathrm{I})$, in part due to their larger body masses.

\section{NDEA and HFD-Induced Islet Hypertrophy and Steatohepatitis (Table 2 and Fig. 2)}

Corresponding with the significantly increased blood glucose and insulin levels, the HFD (Fig. 2B), NDEA (Fig. 2C), and HFD+NDEA (Fig. 2D) treated rats had conspicuously hypertrophied pancreatic islets relative to LFD+Vehicle (Veh) treated controls (Fig. 2A). Islet hypertrophy was not associated with inflammation, necrosis, or histopathologic abnormalities in the exocrine pancreas. Livers of LFD+Veh treated rats had regular chord-like architectures with minimal steatosis and no inflammation (Fig. 2E). NDEA, HFD, and HFD+NDEA treated rats all had mixed patterns of macrovesicular and microvesicular hepatic steatosis (Figs. 2F-2H) with scattered foci of lymphomononuclear cell inflammation (Fig. $2 \mathrm{~F}$ and inset). In addition, livers of NDEA \pm HFD treated rats had conspicuous disorganization of the hepatic chord architecture with scattered foci of hepatocellular necrosis (Figs. 2G-H). A distinguishing feature of the NDEA+HFD exposed livers was the strikingly greater prominence of hepatocellular disorganization and steatosis relative to the other groups (Fig. 2H). None of the livers showed evidence of malignant transformation, i.e. tumors, nodules, or foci of anaplasia. The NDEA \pm HFD abnormalities in liver correspond with the effects of STZ treatment [63-65], and are highly consistent with features of NASH in humans $[1,12,66]$. Biochemical assays confirmed that chronic HFD feeding \pm NDEA treatment caused mild liver injury and steatosis as demonstrated by the significantly increased serum levels of ALT, and hepatic triglyceride content (Table 2). The finding that the NDEA+HFD group had the highest mean levels of serum ALT, and hepatic Nile Red, cholesterol, and triglycerides suggests that the effects of the NDEA plus HFD feeding were additive with respect to liver injury. 
A

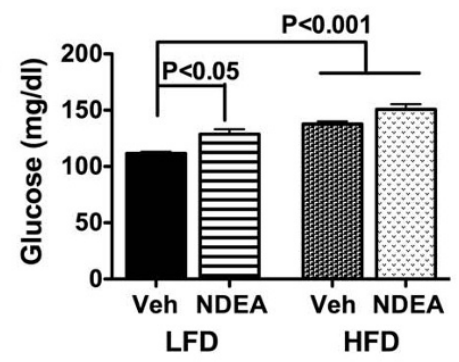

D

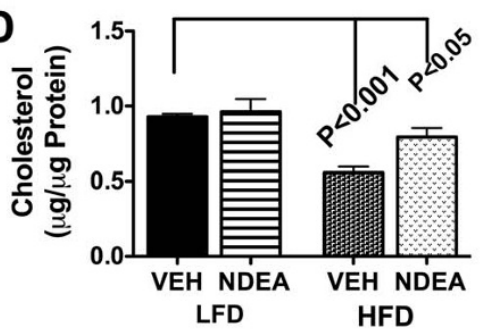

G

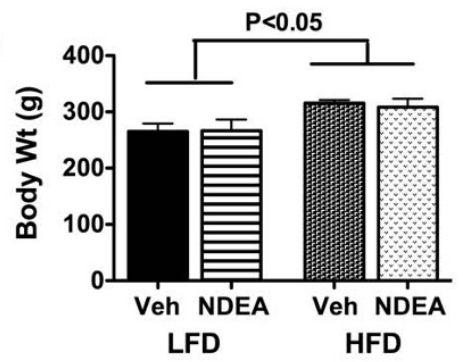

B
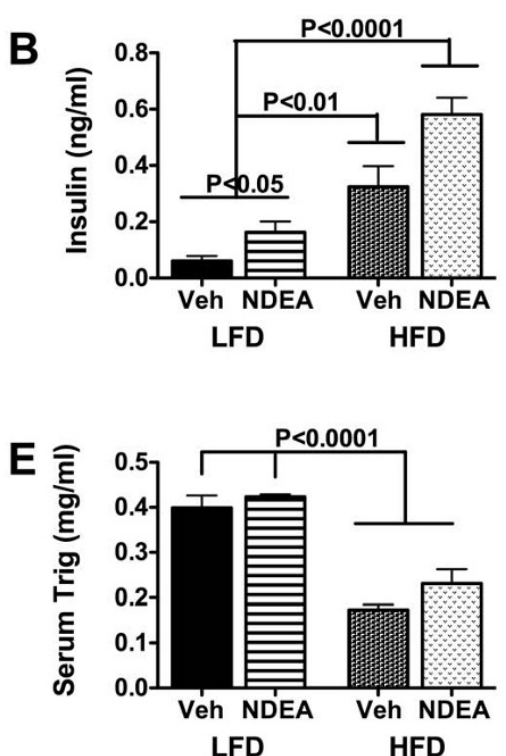

H

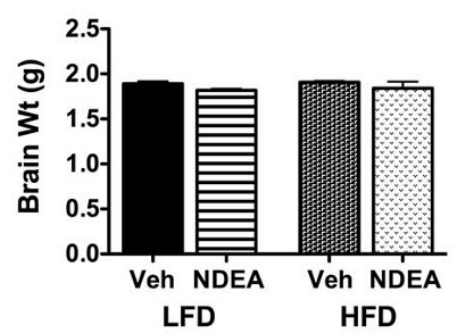

C

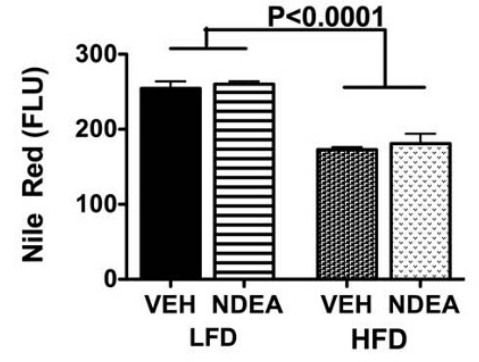

$\mathbf{F}$

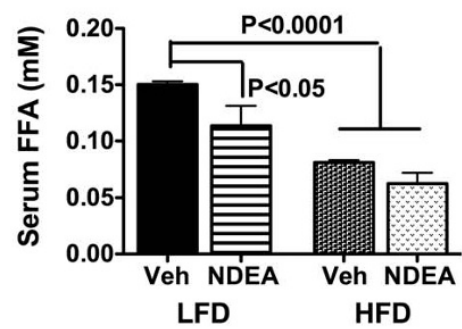

I

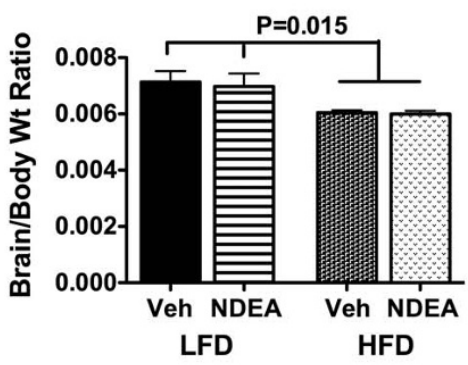

Figure I

NDEA and HFD Feeding Cause T2DM Without Hyper-lipidemia: Long Evans rats were treated with 3 i.p. injections of vehicle or NDEA ( $N=\mid 2$ /group) on alternate days beginning on postnatal day 3 (P3). From P2 I (weaning), rats were fed with high fat (60\% of calories) or low fat ( $5 \%$ of calories) diets for 6 weeks. Serum harvested at the time of sacrifice and after an over-night fast was used to measure (A) glucose, (B) insulin, (C) Nile Red fluorescence (neutral lipids), (D) cholesterol, (E) triglycerides, and (F) free fatty acids. In addition, the mean (G) body weights, $(H)$ brain weights, and (I) calculated brain weight/body weight ratios at the time of sacrifice are shown. Graphs depict the mean \pm S.E.M. results for each group. Data were analyzed using repeated measures ANOVA and the post-hoc Dunn's test. Significant inter-group differences are indicated by the P-values over the bars.

\section{Morris Water Maze Performance (Figure 3)}

On Day 1 of testing (acquisition phase), NDEA treatment, with or without chronic HFD feeding, significantly impaired performance. On Day 2, HFD \pm NDEA treated rats performed significantly worse than LFD+Veh treated controls. On Day 3, the NDEA+HFD group still performed significantly worse than control, and although the NDEA+LFD group had a longer mean latency for locating the hidden platform, the difference from control was not statistically significant. On Day 4, the mean latencies in the NDEA-treated groups remained slightly higher than Veh-treated LFD and HFD fed rats, but the inter-group differences did not reach statistical significance. In essence, although the mean (area under curve) latencies for locating and landing on the platform declined over time in all groups, NDEA treatment alone impaired performance during the acquisition phase, while combined NDEA+HFD exposures significantly impaired both learning and memory.

\section{Neuropathology of NDEA Exposure}

LFD+Veh treated control Ammon's horn (CA1-CA4 regions) of the hippocampus (Fig. 4A) and the temporal cortex (Fig. 4E) were richly populated by neurons with excellent preservation of the architecture (Fig. 4A). Chronic HFD feeding, NDEA-treatment, and NDEA+HFD 

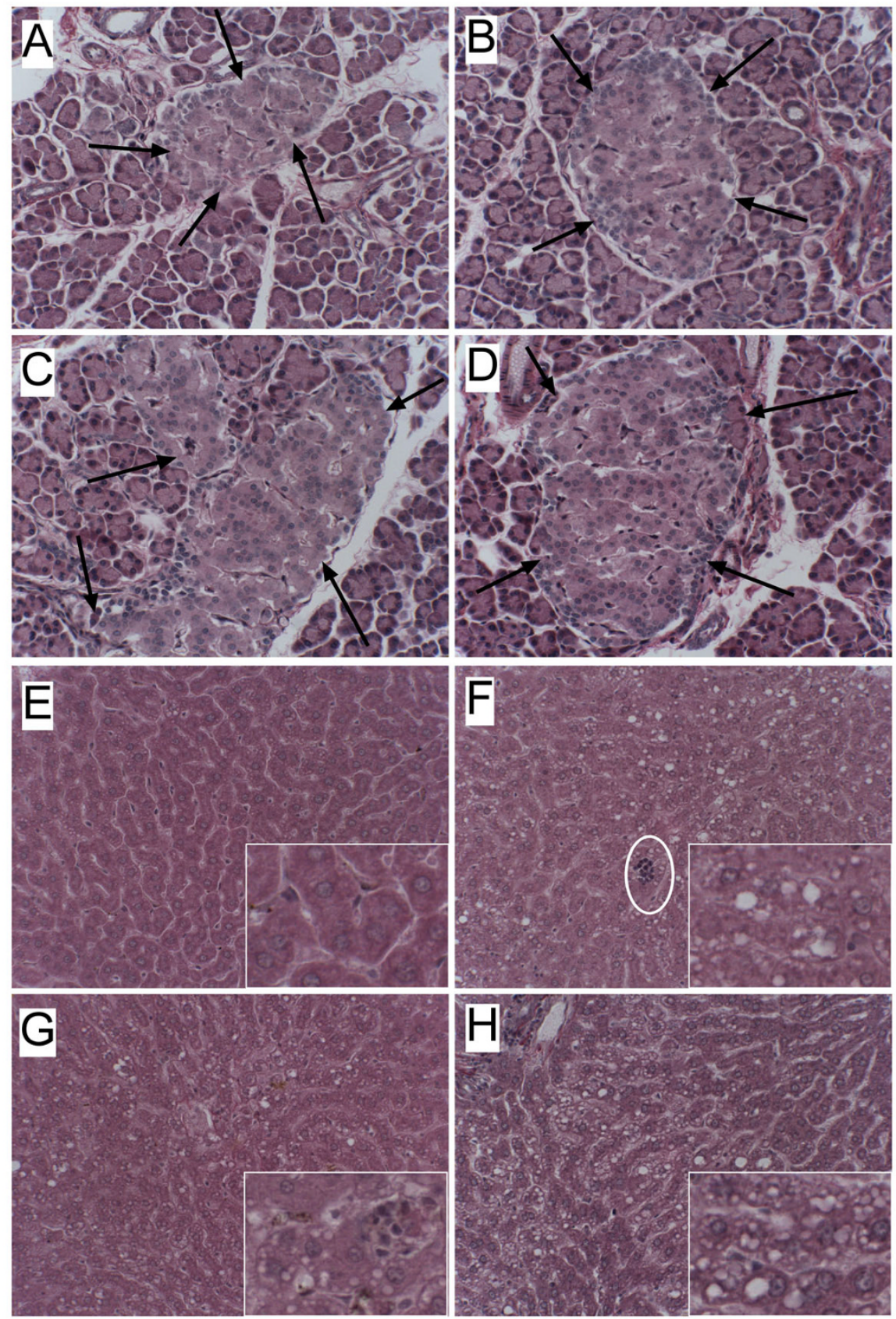

\section{Figure 2}

NDEA Exposure and Chronic HFD Feeding Induce Pancreatic Islet hypertrophy and Steatohepatitis. Long Evans rats were treated with sub-mutagenic doses of NDEA or vehicle (Veh) and then fed with high (HFD) or low fat (LFD) containing chow for 6 weeks (see legend to Figure I). Pancreas and liver tissues were immersion fixed and embedded in paraffin. Histological sections were stained with H\&E. Photomicrographs depict (A-D) pancreas or (E-H) liver from (A, E) LFD+Veh control, (B, F) HFD+Veh, (C, G) LFD+NDEA, and (D, H) HFD+NDEA treated rats. Note enlarged islets in Panels B, C, and D relative to $A$ (arrows). (F) Chronic HFD feeding increased hepatic macrosteatosis (mainly large clear vacuoles; inset) and foci of lymph-mononuclear cell inflammation (encircled) relative to $(E)$ control. Treatment with $(G)$ NDEA resulted in disruption of the regular chord-like arrangement of hepatocytes, increased macro- (large) and microvesicular (small) steatosis, and increased foci of inflammation, and necrosis (inset). $(\mathrm{H})$ NDEA+HFD exposure further disrupted the hepatic chord architecture, and increased the density of lipid vacuoles (inset), and foci of inflammation and necrosis. A-D, Original magnification $400 \times$; E-H Original magnifications, Panels-80x; insets-650x. 
exposure resulted in thinning of CA1 (Figs. 4B-4D), and atrophy of the temporal cortex with loss of neurons manifested by increased inter-neuronal spacing and on-going apoptosis (Figs. 4F-H). In addition, glial cells were conspicuously increased in density in the temporal cortex of NDEA+HFD treated rats (Fig. 4H).

\section{Limited NDEA-Exposure and Chronic HFD Feeding Cause Sustained Abnormalities in Expression of AD-Associated Genes}

To assess long-term effects of NDEA \pm HFD on genes and proteins that are aberrantly expressed in $\mathrm{AD}$, we measured amyloid- $\beta$-precursor protein (A $\beta P P)$, Tau, choline acetyltransferase (ChAT), acetylcholinesterase (AChE), interleukin $1 \beta$ (IL-1 $\beta$ ), IL-6, and tumor necrosis factor-alpha (TNF- $\alpha$ ) mRNA levels by qRT-PCR analysis (Table 3 ), and Tau, phospho-Tau, A $\beta$ PP, A $\beta$ PP-A $\beta$, ChAT, AChE, glyceraldehyde-3-phosphate dehydrogenase (GAPDH), $\beta$-Actin, GFAP, HNE, glycogen synthase kinase $3 \beta$ (GSK-3 $\beta$ ), and pGSK-3 $\beta$ immunoreactivity by ELISA (Figs. 5 and 6 ). The qRT-PCR studies demonstrated that chronic HFD feeding alone reduced $A \beta P P$ gene expression $(\mathrm{P}<0.05)$, while NDEA \pm HFD significantly reduced Tau $(\mathrm{P}<0001)$, ChAT $(\mathrm{P}<0.001)$, and IL-1 $\beta(\mathrm{P}<0.05)$ mRNA expression relative to LFD+Veh treated controls (Table 3). Although A $\beta P P$ mRNA expression was also reduced in the NDEA+HFD group, the difference from control did not reach statistical significance. The mean mRNA levels of AChE, IL- 6 and TNF- $\alpha$ were not significantly altered in the HFD, NDEA, or NDEA+HFD groups relative to control.

ELISA results demonstrated that NDEA treatment alone significantly increased A $\beta$ PP-A $\beta(P<0.001)$ and HNE $(P$ $<0.001)$, and reduced ChAT $(\mathrm{P}<0.01)$ and GFAP $(\mathrm{P}<$ 0.05 ) immunoreactivity relative to control (Figs. 5 and 6). Chronic HFD feeding significantly increased pTau $(\mathrm{P}<$ $0.05)$ and $A \beta P P(P<0.05)$, and reduced the mean levels of Chat $(P<0.05)$ relative to control (Figs. 5 and 6$)$. The combined NDEA+HFD exposures significantly increased the mean ratio of pTau/Tau, indicating relatively higher tau phosphorylation, and reduced the mean levels of Tau $(\mathrm{P}<0.001), \mathrm{A} \beta \mathrm{PP}-\mathrm{A} \beta(\mathrm{P}<0.001), \mathrm{GSK}-3 \beta(\mathrm{P}<0.001)$, ChAT $(\mathrm{P}<0.001)$, GAPDH $(\mathrm{P}<0.001)$, GFAP $(\mathrm{P}<0.001)$, $\beta$-actin $(P<0.05)$, and HNE $(P<0.001)$ relative to control (Figs. 5 and 6). AChE immunoreactivity was not significantly altered by NDEA and/or HFD feeding. Although GSK-3 $\beta$ immunoreactivity was reduced by NDEA+HFD exposure, the relative preservation of the pGSK-3 $\beta /$ GSK$3 \beta$ ratio indicates that constitutive GSK-3 $\beta$ activity in brain was not significantly altered by these treatments. Therefore, the increased pTau/Tau ratio measured in the same samples may have been mediated by kinases other than GSK-3 $\beta$. The additive effects of HFD plus NDEA exposure were demonstrated by the fact that the greater reductions in ChAT, tau, $\beta$-actin, GFAP, and GAPDH, and increases in the mean levels of pTau or pTau/Tau ratio compared with the effects of either treatment/exposure alone.

\section{Limited NDEA-Exposure and Chronic HFD Feeding Cause Sustained Impairments in Insulin/IGF Signaling Mechanisms in the Brain}

QRT-PCR analysis demonstrated significantly increased levels of insulin $(P<0.05)$, IGF-1 $(P<001)$ and IRS-4 $(P$ $<0.001)$ in rats exposed to NDEA only, increased insulin $(\mathrm{P}<0.01)$ and IGF-2 receptor $(\mathrm{P}<0.05)$, and decreased IGF-1, IGF-1 receptor $(\mathrm{P}<0.05)$, and IRS-1 in rats chronically fed with the HFD, and reduced IGF-1 $(\mathrm{P}<0.05)$, insulin receptor $(\mathrm{P}<0.05)$, IGF-1 receptor $(\mathrm{P}<0.05)$, and IRS-1 $(\mathrm{P}<0.001)$ in rats treated with NDEA+HFD relative to LFD fed controls (Table 4). Moreover, insulin, IGF-1, insulin receptor, IGF-2 receptor, IRS-1, IRS-2, and IRS-4 mRNA levels were lowest in the NDEA+HFD treated group. These impairments in the expression of genes needed for proper insulin and IGF signaling are reminiscent of those detected in human brains with $\mathrm{AD}$ $[34,51,67]$.

\section{NDEA and Chronic HFD Feeding Cause Hepatic and Brain Insulin and/or IGF-I Resistance}

NDEA exposure significantly reduced IGF-1 receptor binding in liver $(P<0.001)$. Chronic HFD feeding significantly reduced IGF-1 receptor binding in liver $(\mathrm{P}<0.05)$, and both IGF-1 $(\mathrm{P}<0.01)$ and insulin $(\mathrm{P}<0.01)$ receptor binding in brain. Combined NDEA+HFD exposures significantly reduced both insulin receptor binding in liver

Table 2: Assays of Liver Injury or Hepatic Steatosis

\begin{tabular}{|c|c|c|c|c|c|c|}
\hline Assay & LFD+VEH & LFD+NDEA & HFD+VEH & HFD+NDEA & F-Ratio & P-Value \\
\hline Serum ALT (U/L) & $17.3 \pm 0.9$ & $23.8 \pm 3.9$ & $30.6 \pm 1.8^{* *}$ & $33.5 \pm 2.1^{* *}$ & 10.08 & $<0.0001$ \\
\hline 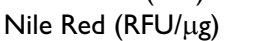 & $111.0 \pm 2.6$ & $128.3 \pm 15.0$ & $122.7 \pm 6.1$ & $|47.9 \pm 6 .|^{*}$ & 2.77 & 0.06 \\
\hline Cholesterol (ng/mg) & $360.5 \pm 20.2$ & $340.1 \pm 33.9$ & $435.4 \pm 21.9$ & $458.4 \pm 19.7^{*}$ & 5.02 & 0.011 \\
\hline Triglycerides ( $\mu \mathrm{g} / \mathrm{mg})$ & $11.2 \pm 1.5$ & $10.8 \pm 2.0$ & $17.1 \pm 0.8^{*}$ & $21.0 \pm 1.4^{* *}$ & 10.3 & 0.0003 \\
\hline
\end{tabular}

$\S A L T=$ alanine transaminase, Nile Red, cholesterol, and tryglyceride levels were measured in liver tissue. RFU/ $\mu \mathrm{g}=$ relative fluorescence units; Nile red, cholesterol and triglyceride measurements are relative to liver. Inter-group comparisons were made using ANOVA tests. For all measurements, $\mathrm{df}=3 / 36$. Significant differences relative to the LFD control group were demonstrated using the Dunnett's post-hoc multiple comparison test ( $* \mathrm{P}<0.05$; $* * \mathrm{P}<0.01$; $* * * P<0.001)$. 


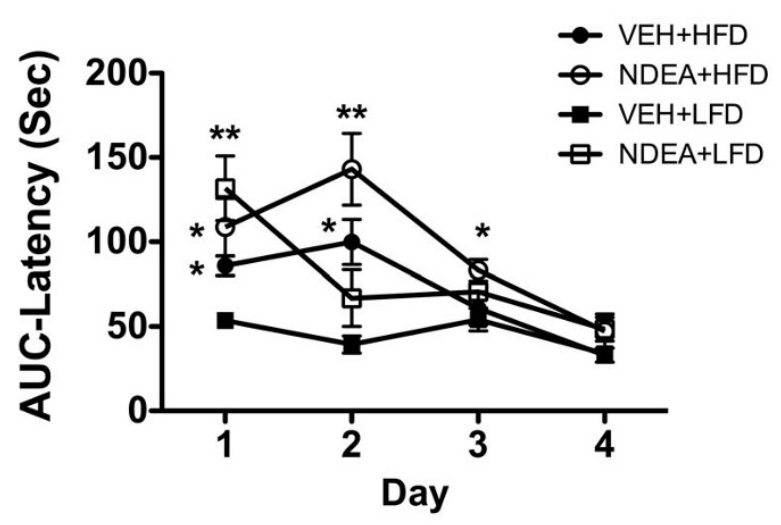

Figure 3

NDEA Treatment and Chronic HFD Feeding Impair Spatial Learning and Memory: Long Evans rats were treated with NDEA or vehicle (VEH) by i.p. injection ( $N=$ I 2/group), and then chronically fed with high fat (HFD) or low fat (LFD) containing chow for 6 weeks (see Figure Legend I). Rats were subjected to Morris Water Maze testing on 4 consecutive days. On Day I, the platform was visible, but on Days 2-4, the platform was submerged, and on Days 3-4, the water entry quadrant was randomized. On each testing day, rats were given 3 trials, with a maximum of 120 seconds allowed to land on the platform, beyond which they were guided. Area under curve (AUC) was calculated for each series of trials each day. Graphs depict the mean \pm S.E.M. AUC latencies for each group on each day of testing. Data were analyzed using the KruskalWallis one-way ANOVA and Dunn's multiple comparison post-hoc test for significance. Significant $P$-values relative to control (VEH+LFD) are indicated by asterisks (*P < 0.05 ; **P $<0.01)$.

$(\mathrm{P}<0.5)$ and brain $(\mathrm{P}<0.001)$, and IGF-1 receptor binding in liver $(P<0.001)$ and brain $(P<0.001)$ (Fig. 7$)$. In essence, insulin receptor binding was mainly associated with chronic HFD feeding, with or without antecedent NDEA exposure. However, the inhibitory effects of HFD feeding and NDEA exposure appeared to be additive with respect to insulin receptor binding in liver, and IGF-1 receptor binding in brain. These results suggest that the NDEA exposure and chronic HFD-feeding differentially mediate insulin and/or IGF resistance in liver and brain, indicating that a given exposure can adversely affect organ function in different ways and to dissimilar degrees.

\section{NDEA-Mediated Increases in Pro-Ceramide Gene Expression}

We investigated the potential role of pro-ceramide genes as mediators of NDEA \pm HFD associated neurodegeneration because ceramides: 1 ) can be generated in brain and liver $[68-71]$; 2) cause cytotoxicity and insulin resistance $[71,72]$; and 3 ) are increased in brains with neurodegen- eration [68,73-75]. Moreover, recent studies showed that increased ceramide gene expression in liver correlates with neurodegeneration in the context of obesity with T2DM and NASH [38], and that in vitro ceramide exposure causes neurodegeneration [72]. To assess the potential role of ceramides and their sources in relation to neurodegeneration and insulin/IGF-1 resistance, we measured mRNA levels of ceramide synthases (CER), UDP glucose ceramide glycosyltransferase (UGCG), serine palmitoyltransferase (SPTLC), and sphingomyelin phosphodiesterases (SMPD) in liver and temporal lobe, due to their demonstrated relevance to neurodegeneration $[38,72]$. The qRT-PCR analyses revealed significantly higher mean levels of all 5 genes in livers of NDEA \pm HFD-treated relative to LFD+Veh or HFD+Veh treated rats (Fig. 8). However, there was no additional burden produced by chronic HFD, indicating that the NDEA exposure was sufficient to significantly alter pro-ceramide gene expression in the direction of increased ceramide production through both biosynthesis and degradation pathways. With regard to the temporal lobe, the effects of HFD and NDEA treatment were more varied compared with liver. NDEA treatment, with or without HFD feeding, increased expression of CER4, UGCG and SMPD3, but decreased CER2, CER5, and SPTLC1 mRNA levels (Table 5). In addition, HFD feeding alone significantly increased SMPD1 and decreased SPTLC1 expression relative to control. Therefore, both NDEA and HFD feeding contributed to increased ceramide generation in the brain, although some enzymes involved in ceramide biosynthesis were down-regulated, possibly as a protective/compensatory mechanism to modulate its accumulation.

\section{Discussion}

We examined the degree to which limited early life NDEA exposure exacerbates the effects of later chronic HFD feeding on subsequent development of T2DM, NASH, and neurodegeneration. The relevance of this work to human disease is that, morbidity and mortality from major insulin-resistance diseases have escalated over the past several decades. Such trends more likely correspond with exposure rather than genetic etiologies. Our principal hypothesis is that shifts in lifestyles have led modern societies to chronically consume excess fats, and also to increase our exposures to pathogenic agents that cause insulin resistance. We focused our investigations on nitrosamines, particularly NDEA, because in previous studies, STZ, a nitrosamine-related chemical, was demonstrated to be mutagenic in high doses [17], and to cause insulin-resistance diseases at lower levels or after limited durations of exposure [18-25,76]. However, since STZ is not generally available in the environment or foodstuffs, whereas nitrosamines and related compounds are widely present in our environment and contaminate our foods, we hypothesize that limited or chronic low-level exposures to nitro- 

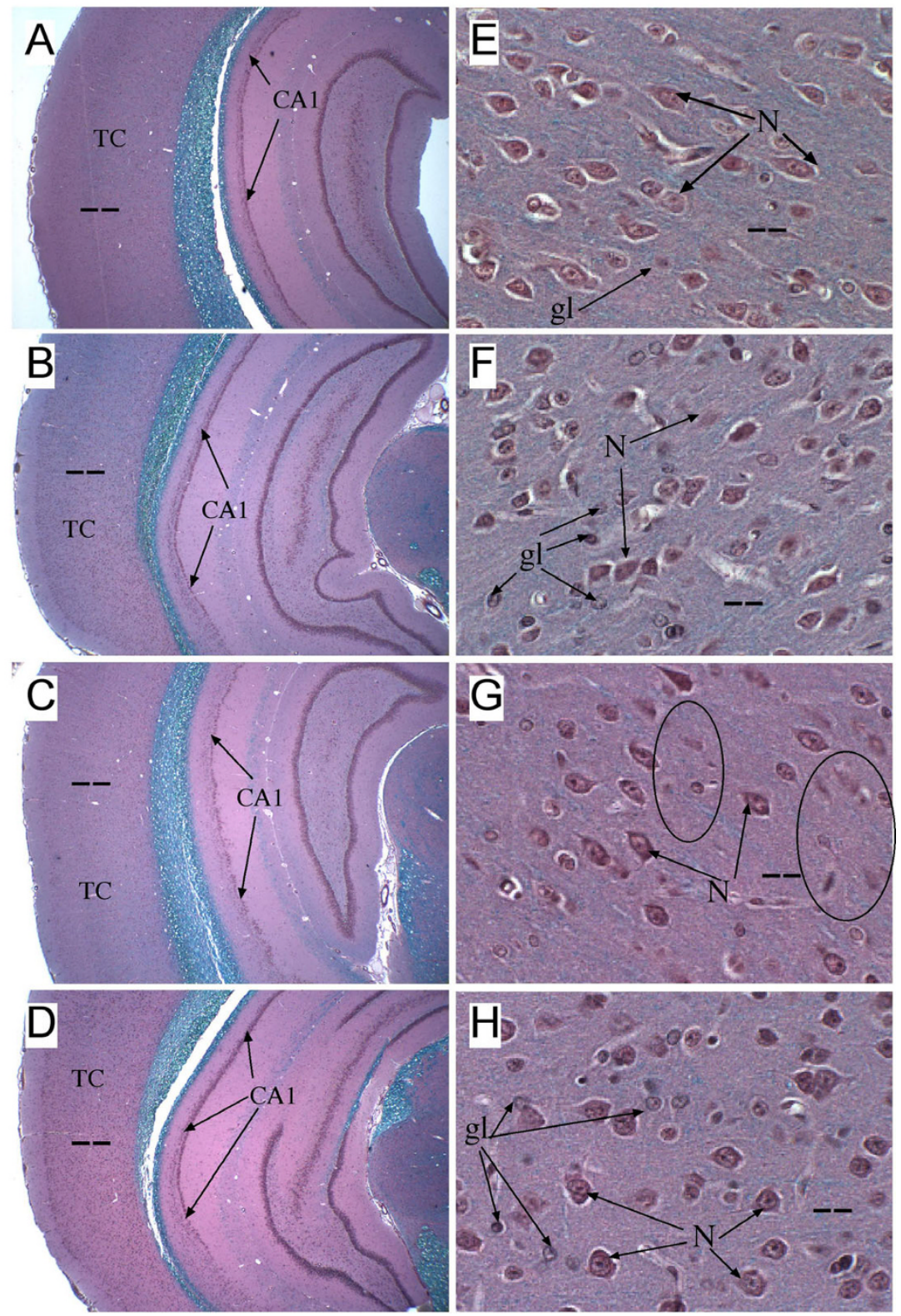

Figure 4

Hippocampus and Temporal Lobe Degeneration Following NDEA-Exposure and/or HFD Feeding: Long Evans rats treated with NDEA or vehicle (Veh) by i.p. injection ( $N=$ I 2/group), and then chronically fed with high fat (HFD) or low fat (LFD) containing chow for 6 weeks (see Figure Legend I). Brains were immersion fixed and embedded in paraffin. Histological sections were stained with Luxol fast blue, H\&E. Blue staining corresponds to myelinated fibers and tracts. Photomicrographs depict (A-D) low magnification images of temporal cortex (TC) and hippocampal formation and $(\mathrm{E}-\mathrm{H})$ high magnification images of the temporal cortex. Note the thinning/reduced cell density within the CAI region (Segment I of Ammon's Horn; arrows) of the hippocampal formation and slight thinning of the TC in brains of (B) Veh+HFD, (C) NDEA+LFD, and (D) NDEA+HFD treated rats relative to control (A) Veh+LFD). Higher magnification images of TC show (E) abundant pyramidal neurons $(N)$ with regular organization and scattered glia ( $g l)$ in LFD+Veh treated control brains, (F) neuronal atrophy and apoptosis (N; arrows) and increased glia (gl) in Veh+HFD treated rats, and (G, H) conspicuous neuronal loss with small clusters of apoptotic cells (encircled) in NDEA \pm HFD-treated rats. In addition, as observed in the HFD-fed rat brains, glial cells were conspicuously increased relative to neurons in the $(H)$ HFD+NDEA treated temporal cortex. Original magnifications: A-D, 40×; E-H, 400×. (Scale bar A-D, 200 microns; E-H 25 microns). 
samines account for the current insulin resistance disease epidemic in the United States. Moreover, given the clear role of high dietary fat intake as a mediator of obesity, T2DM, NAFLD/NASH, and cognitive impairment, we propose that the combined effects of HFD and NDEA exposure additively promote development of insulin resistance diseases.

The knowledge that: 1) human nitrosamine exposures occur through many sources including, processed and preserved foods, tobacco smoke (direct or second hand), and nitrate-containing fertilizers; and 2) nitrosamines are mutagenic and cause tissue injury in manners similar to STZ $[17,19,27,29]$, prompted us to consider whether nitrosamines could have pathogenic roles in our insulin resistance diseases epidemic. Although epidemiologic studies have correlated obesity and high dietary fat intake with rising rates of T2DM, NASH, and cognitive impairment $[1-3,5,6,77]$, experimental data are somewhat varied depending on the model, and no studies have demonstrated that obesity/T2DM is sufficient to cause significant AD-type neurodegeneration with cognitive impairment. In fact, the evidence convincingly informs us that these factors alone are not sufficient, and instead serve as co-factors in the pathogenesis of neurodegeneration, including AD. Therefore, we propose that high dietary fat intake exacerbates the adverse effects of limited NDEA or other nitrosamine exposures to cause insulin resistance diseases.

We generated an experimental in vivo model in which rat pups were treated with NDEA at doses that were 5- to 500fold lower than the cumulative doses used to cause cancer [78-81], and beginning in early adolescence, we pair-fed the rats with high $(60 \%)$ or low $(10 \%)$ fat content diets. The use of young rats in these studies was inspired in part by longitudinal studies of nuns demonstrating that neurocognitive abnormalities occur decades earlier than the onset of dementia, indicating that very early life exposures may predispose individuals to develop $\mathrm{AD}$, as well as other neurodegenerative diseases [52,53], perhaps through epigenetic events such as DNA methylation or gene imprinting. Correspondingly, there is evidence that DNA methylation and other epigenetic changes in DNA increase with aging [82], and likely contribute to the pathogenesis of diseases such as diabetes and neurodegeneration [82,83]. Moreover, there is experimental evidence that nitrosamines, as well as other adduct forming toxins that contaminate foods, can mediate DNA methylation $[84,85]$. Since it could take years for epigenetic modifications to cause disease, and the findings in the "Nun Study" suggest that early events in life predispose individuals to develop $\mathrm{AD}$ [53], we utilized an experimental animal model in which low-dose NDEA exposures were administered early in life. The subsequent chronic HFD feeding during adolescence, also fits with the human disease model. Therefore, our experimental approach enabled us to examine effects of early life NDEA exposure on later cognitive function and neurodegeneration in the context of excess caloric intake, which is one of the major modifying factors correlated with insulin resistance diseases in our society.

Although the HFD feeding and NDEA treatments significantly increased body weight relative to control, and caused T2DM, characterized by fasting hyperglycemia, hyperinsulinemia, and pancreatic islet hypertrophy $[86,87]$, the rats were not obese and they did not have hyperlipidemia. On the other hand, the NDEA \pm HFD groups had steatohepatitis with hepatic insulin and/or IGF-1 resistance which were more pronounced in rats that had the combined versus individual NDEA or HFD exposures. This suggests that HFD and NDEA function additively to promote NASH and T2DM. In contrast to the C57BL/6 mouse model of HFD feeding in which NASH was associated with obesity, T2DM, and hyperlipidemia $[38,39]$, the serological profile in the present model provided minimal evidence of hepatic insulin/IGF resistance. Since the serum ALT levels were increased in the HFD groups, perhaps biomarkers of hepatic injury in individuals with T2DM should be regarded as a potential indicator of steatohepatitis.

The NDEA treatments and HFD feedings independently caused significant deficits in spatial learning, and the combined exposures had the added effect of impairing learning and memory, again suggesting that the adverse effects were additive. Therefore, curbing either or both exposures could help prevent subsequent development of cognitive impairment. A second point is that, although the NDEA was delivered within a brief window early in life, its impact on cognitive function was sustained in the adults, similar to the effects of ic-STZ treatment $[22,25]$. The mechanism underlying these prolonged and possibly progressive deficits may reside in the fact that nitrosamines promote the formation of adducts that can serve as persistent sources of oxidative stress, DNA damage, and protein mal-folding or dysfunction $[8,9,26,88]$, and ultimately lead to epigenetic changes in gene expression.

Reduced levels of ChAT expression were observed in brains of HFD, NDEA, and NDEA+HFD treated rats. In addition, NDEA exposure without HFD feeding reduced GFAP, but increased HNE and A $\beta$ PP-A $\beta$, while NDEA+HFD reduced GFAP, GAPDH, Tau, pGSK-3 $\beta$, A $\beta P P-A \beta$, and HNE immunoreactivities, and Tau and IL$1 \beta$ mRNA, but increased pTau and the pTau/Tau ratio. Since HFD feeding alone had minimal effects on these biomarkers of neurodegeneration, the differences in reaction to NDEA versus NDEA+HFD could be attributed to 

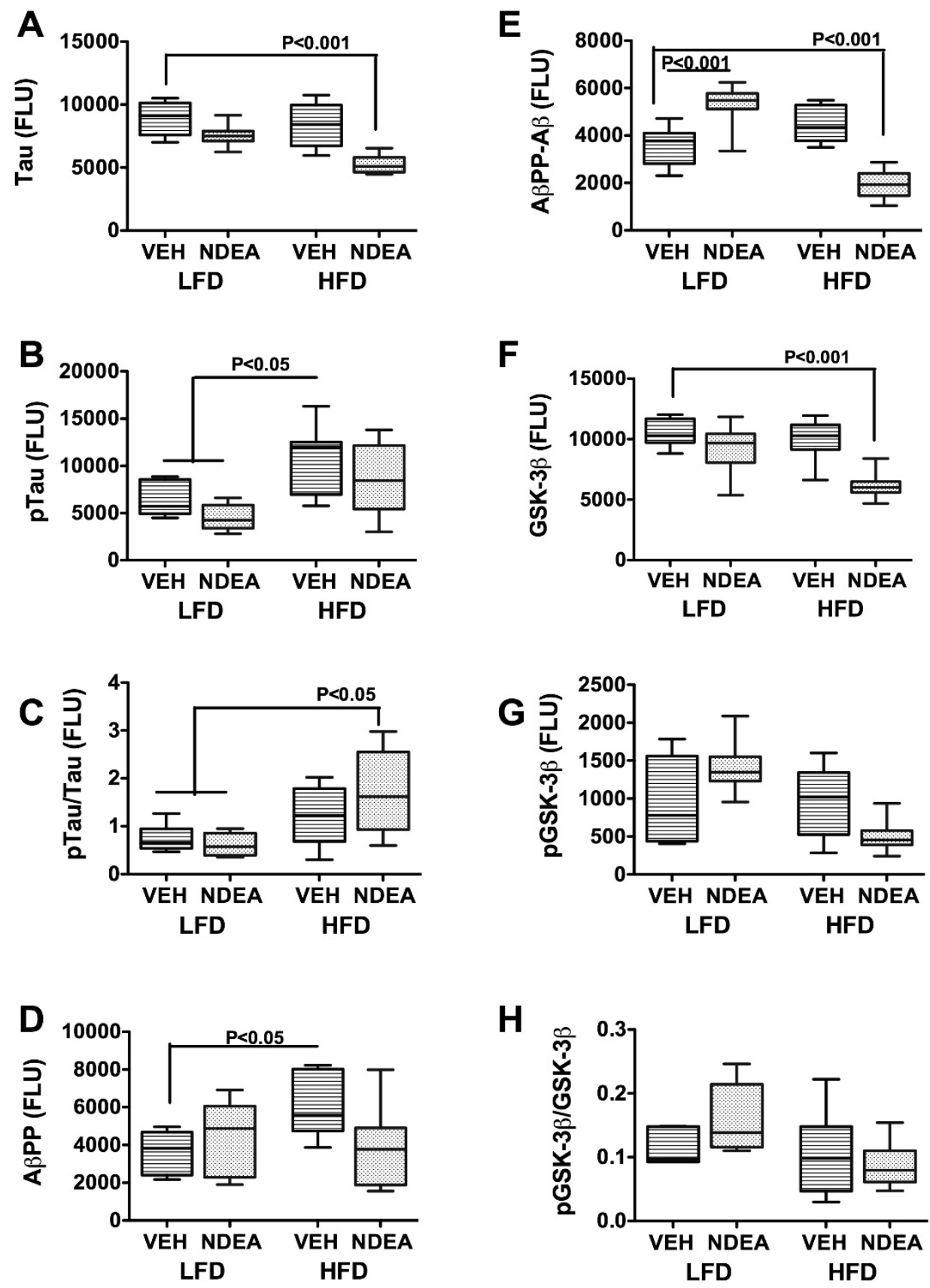

Figure 5

Effect of NDEA Exposure and Chronic HFD Feeding on Molecular Indices of Neurodegeneration. Long Evans rats were treated with NDEA or vehicle (VEH) by i.p. injection ( $N=12 /$ group), and then chronically fed with high fat (HFD) or low fat (LFD) containing chow for 6 weeks (see Figure Legend I). Temporal lobe protein homogenates were used to measure

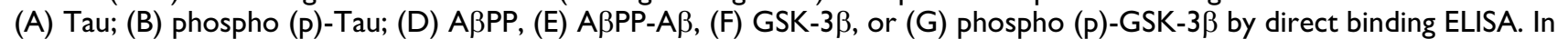
addition, the ratios of $(C)$ pTau/Tau and $(H)$ pGSK-3 $\beta / G S K-3 \beta$ were calculated. Immunoreactivity was detected with HRP-conjugated secondary antibody and Amplex Red soluble fluorophor. Fluorescence light units (FLU) were measured (Ex $579 \mathrm{~nm} / \mathrm{Em}$ $595 \mathrm{~nm}$ ) in a Spectromax M5, and results were normalized to protein content in the wells. Box plots depict mean \pm S.E.M of results. Inter-group comparisons were made using ANOVA with the post-hoc Bonferroni test of significance. Significant $P$-values are indicated within the panels. 

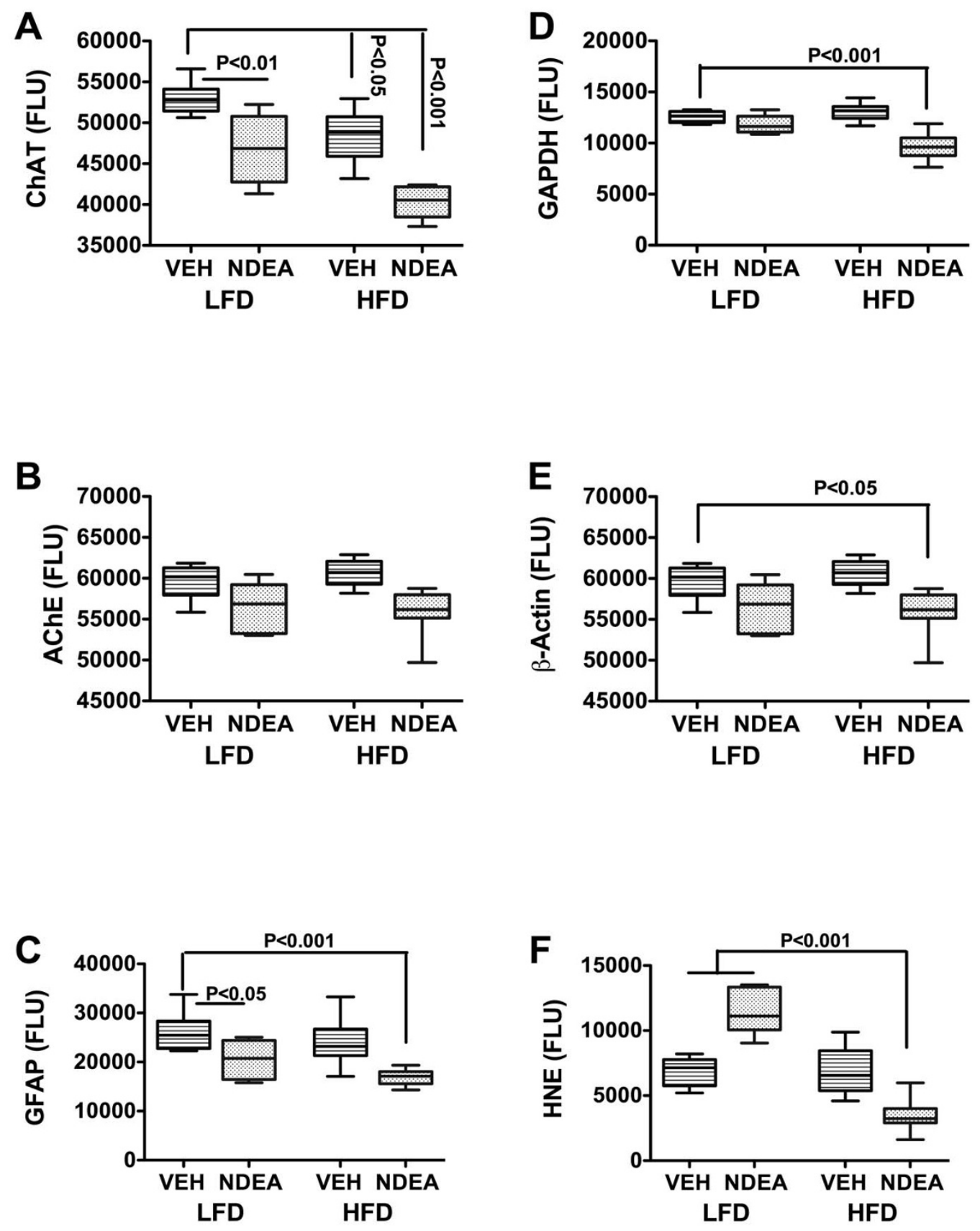

Figure 6

Effect of NDEA Exposure and Chronic HFD feeding on Molecular Indices of Oxidative Stress and Neurodegeneration. Long Evans rats were treated with NDEA or vehicle $(\mathrm{VEH})$ by i.p. injection $(\mathrm{N}=12$ /group), and then chronically fed with high fat (HFD) or low fat (LFD) chow for 6 weeks (see Figure Legend I). Temporal lobe protein homogenates were used to measure (A) choline acetyltransferase (ChAT), (B) acetylcholinesterase (AChE), (C) GFAP, (D) GAPDH, (E) $\beta$-Actin, or (F) 4-hydroxynonenal (HNE) by direct binding ELISA. Immunoreactivity was detected with HRP-conjugated secondary antibody and Amplex Red soluble fluorophor. Fluorescence light units (FLU) were measured (Ex $579 \mathrm{~nm} / \mathrm{Em} 595 \mathrm{~nm}$ ) in a Spectromax $M 5$, and results were normalized to sample protein content in the wells. Box plots depict mean \pm S.E.M of results. Inter-group comparisons were made using ANOVA with the post-hoc Bonferroni test of significance. Significant P-values are indicated within the panels. 
Table 3: Effects of High Fat Diet and NDEA Exposure on Biomarkers of AD and Neuro-inflammation in Temporal Lobe

\begin{tabular}{|c|c|c|c|c|c|c|}
\hline & LFD & LFD+NDEA & HFD & HFD+NDEA & F-Ratio & P-Value \\
\hline $\mathrm{A} \beta \mathrm{PP}$ & $4.392 \pm 0.423$ & $3.966 \pm 0.458$ & $3.026 * \pm 0.215$ & $3.228 \pm 0.299$ & 3.099 & 0.039 \\
\hline Tau & $3.380 \pm 0.272$ & $2.689 \pm 0.255$ & $3.310 \pm 0.270$ & $1.938 * * * \pm 0.209$ & 7.023 & 0.001 \\
\hline ChAT & $0.170 \pm 0.016$ & $0.147 \pm 0.026$ & $0.164 \pm 0.014$ & $0.115 \S \pm 0.007$ & & 0.001 \\
\hline $\mathrm{AChE}$ & $0.824 \pm 0.081$ & $1.080 \pm 0.137$ & $0.747 \pm 0.099$ & $0.795 \pm 0.048$ & & \\
\hline IL-I $\beta$ & $0.047 \pm 0.004$ & $0.047 \pm 0.010$ & $0.052 \pm 0.005$ & $0.023^{*} \pm 0.003$ & 4.627 & 0.008 \\
\hline IL6 & $0.052 \pm 0.006$ & $0.045 \pm 0.006$ & $0.050 \pm 0.005$ & $0.034 \pm 0.005$ & & \\
\hline TNF- $\alpha$ & $0.022 \pm 0.002$ & $0.035 \pm 0.005$ & $0.034 \pm 0.005$ & $0.036 \pm 0.004$ & & \\
\hline
\end{tabular}

Gene expression was measured by $\mathrm{qRT}-\mathrm{PCR}$ with results normalized to $18 \mathrm{~S}$ rRNA (see Methods). Values correspond to mRNA/I8S $\times 10^{-6}$. Intergroup comparisons were made using ANOVA tests. For all measurements, $\mathrm{df}=3 / 36$. Significant differences relative to the LFD control group were demonstrated using the Dunnett's post-hoc multiple comparison test (*P $<0.05$; ${ }^{* * P}<0.01$; $\left.{ }^{* * *} \mathrm{P}<0.00 \mathrm{I}\right)$. For ChAT, the ANOVA test was not significant, but the mRNA levels were significantly different from control in the HFD+NDEA treated group by T-test analysis.

interactive or amplifying effects of chronic HFD feeding/ T2DM on early life, low-level NDEA exposure. This phenomenon was particularly noticeable with respect to the reductions in ChAT, which were modest in brains of rats exposed to NDEA or the HFD, but striking in brains exposed to NDEA plus HFD.

The NDEA-associated reductions in GFAP, Tau, and ChAT expression in brain are of interest because similar observations were made in humans with $\mathrm{AD}$, and in the ic-STZ experimental animal model of AD-type neurodegeneration $[22,25,51]$. The reduced levels of GFAP suggest that glia (astrocytes) are targets of neurodegeneration. The reductions in Tau and ChAT expression are noteworthy because both genes are regulated by insulin/IGF stimulation, their expression levels are reduced in $\mathrm{AD}$ [51], and insulin/IGF resistance was demonstrated to be a prominent adverse effect of limited and low-level NDEA exposure resulting in neurodegeneration with cognitive dysfunction, as also occurs in AD [51]. Similarly, the relative increases in pTau, and reductions in pGSK-3 $\beta$ (inactive), GAPDH, and $\beta$-actin in the NDEA+HFD group reflect adverse effects of impaired insulin/IGF signaling with cytoskeletal collapse, increased oxidative stress, and reduced energy metabolism, similar to the effects of both i.c. STZ treatment in rats and sporadic $\mathrm{AD}$ in humans [51].

The effects of HFD, NDEA, or both exposures on A $\beta P P$ and $A \beta P P-A \beta$ were varied, but the most striking findings were significantly increased levels of $A \beta P P-A \beta$ in NDEAtreated rats, and paradoxically decreased levels of A $\beta P P-$ $\mathrm{A} \beta$ in brains of NDEA+HFD treated rats. Similarly, HNE immunoreactivity was also increased in brain by limited peripheral NDEA exposure, but these adverse effects of NDEA were abolished by chronic HFD feeding. The findings with respect to NDEA on A $\beta$ PP-A $\beta$ and HNE are consistent with previous observations that oxidative stress promotes $\mathrm{A} \beta \mathrm{PP}-\mathrm{A} \beta$ accumulation and lipid peroxidation in the CNS [89]. On the other hand, it appears that HFD feeding may have been somewhat protective, perhaps due to alterations in membrane lipid composition leading to enhanced intracellular signaling [90]. The fact that ChAT expression and cognitive function were most impaired in the NDEA+HFD group relative to control vis-à-vis low levels of $A \beta P P-A \beta$ highlights the controversial role of A $\beta P P-$ $\mathrm{A} \beta$ accumulation in relation to cognitive impairment in $\mathrm{AD}$.

Table 4: Effects of High Fat Diet and NDEA Exposure on Biomarkers of Insulin and IGF Resistance in Temporal Lobe

\begin{tabular}{lcccrrr}
\hline & LFD & LFD+NDEA & HFD & HFD+NDEA & F-Ratio & P-Value \\
\hline Insulin & $0.093 \pm 0.011$ & $0.155^{*} \pm 0.015$ & $0.18 I^{* *} \pm 0.028$ & $0.069 \pm 0.008$ & 9.1450 & $<0.0001$ \\
IGF-I & $0.170 \pm 0.012$ & $0.253^{* *} \pm 0.029$ & $0.10 I^{*} \pm 0.015$ & $0.10 I^{*} \pm 0.007$ & 16.4000 & $<0.0001$ \\
IGF-2 & $2.336 \pm 0.285$ & $2.414 \pm 0.675$ & $1.718 \pm 0.219$ & $2.004 \pm 0.179$ & 19.3400 & $<0.0001$ \\
Insulin R & $1.060 \pm 0.129$ & $0.977 \pm 0.070$ & $0.997 \pm 0.117$ & $0.634^{*} \pm 0.073$ & 3.6360 & 0.0210 \\
IGF-IR & $0.814 \pm 0.111$ & $1.027 \pm 0.098$ & $0.482^{*} \pm 0.047$ & $0.485^{*} \pm 0.059$ & 10.3700 & $<0.0001$ \\
IGF-2R & $0.649 \pm 0.049$ & $0.721 \pm 0.107$ & $0.893^{*} \pm 0.051$ & $0.540 \pm 0.053$ & 4.5660 & 0.0080 \\
IRS-I & $0.393 \pm 0.031$ & $0.439 \pm 0.040$ & $0.244^{* *} \pm 0.013$ & $0.185^{* * *} \pm 0.016$ & 19.3400 & $<0.0001$ \\
IRS-2 & $1.678 \pm 0.211$ & $2.652 \pm 0.406$ & $1.127 \pm 0.104$ & $1.300 \pm 0.166$ & 1500 \\
IRS-4 & $0.029 \pm 0.005$ & $0.153^{* * *} \pm 0.030$ & $0.049 \pm 0.007$ & $0.025 \pm 0.004$ & 15.0000 & $<0.0001$ \\
\hline
\end{tabular}

Gene expression was measured by qRT-PCR with results normalized to $18 \mathrm{~S}$ rRNA (see Methods). Values correspond to $\mathrm{mRNA} / 18 \mathrm{~S} \times 10^{-6}$. Intergroup comparisons were made using ANOVA tests. For all measurements, $\mathrm{df}=3 / 36$. Significant differences relative to the LFD control group were demonstrated using the Dunnett's post-hoc multiple comparison test $(* \mathrm{P}<0.05 ; * * \mathrm{P}<0.0 \mathrm{I}$; *** $\mathrm{P}<0.00 \mathrm{I})$. 

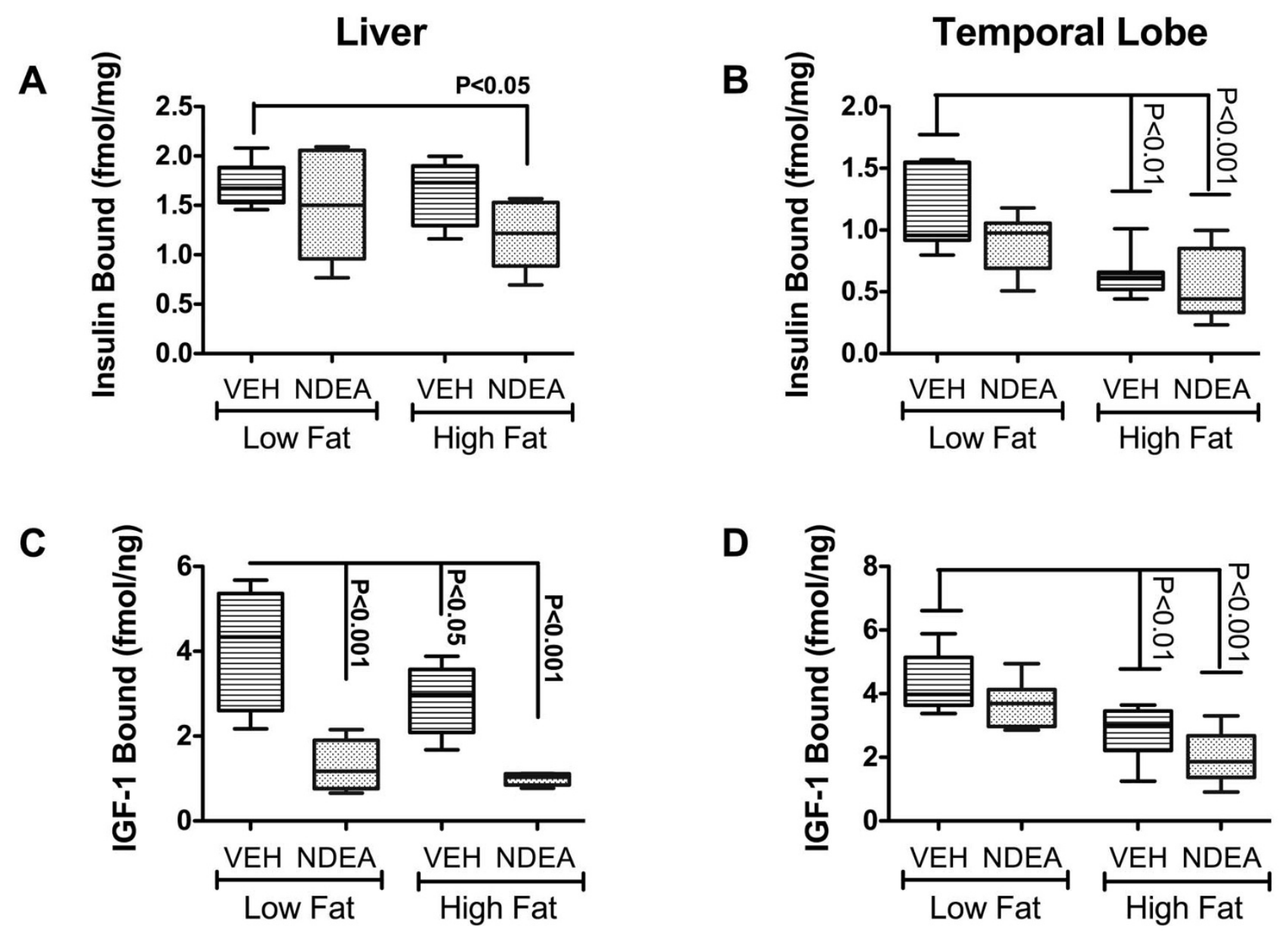

\section{Figure 7}

NDEA Exposure and Chronic HFD Feeding Impair Insulin and IGF-I Receptor Binding in Liver and Brain. Long Evans rats were treated with NDEA or vehicle $(\mathrm{VEH})$ by i.p. injection $(N=12 /$ group), and then chronically fed with high fat (HFD) or low fat (LFD) containing chow for 6 weeks (see Figure Legend I). Competitive equilibrium binding studies were used to measure specific insulin and IGF-I binding to their corresponding receptors. Reactions were incubated with $50 \mathrm{nCi} / \mathrm{ml}$ of ['25I] (2000 Ci/mmol; 50 pM) insulin or IGF-I in binding buffer in the presence or absence of $0.1 \mu M$ unlabeled ligand. Radiolabeled bound ligand was harvested onto 96 -well GF/C filter plates and measured in a TopCount. Specific binding was calculated by subtracting non-specifically bound from the total bound isotope. Box plots depict mean \pm S.D. of specific binding for (A, B) insulin and (C, D) IGF-I in (A, C) liver and (B, D) temporal lobe. Inter-group comparisons were made using ANOVA with the post-hoc Bonferroni test of significance. Significant $P$-values are indicated within the panels.

NDEA exposure and HFD feeding independently impaired insulin and IGF-1 signaling mechanisms in liver and brain, and in general, the combined exposures further reduced both hepatic and brain insulin and IGF-1 receptor binding compared with HFD feeding alone. Therefore, brain and hepatic insulin/IGF-1 resistance can be effectuated by either insult. Although impairments in binding to the insulin and IGF-1 receptors in brain could be explained in part by reduced expression of those receptors or receptor-bearing cells in rats treated with NDEA+HFD, generally, this was not the case for the NDEA-treated or
HFD-fed groups in which the receptor expression was either elevated or similar to control. Most likely, the impaired receptor binding with attendant reduced expression of IRS signaling molecules mediated the insulin/IGF resistance. Moreover, the reductions in IGF-1 expression could account for progressive loss of IGF-1 receptor bearing cells in vivo. In some instances, ligand expression was increased, suggesting that compensatory responses had occurred due to insulin/IGF-1 resistance as occurs in T2DM. 

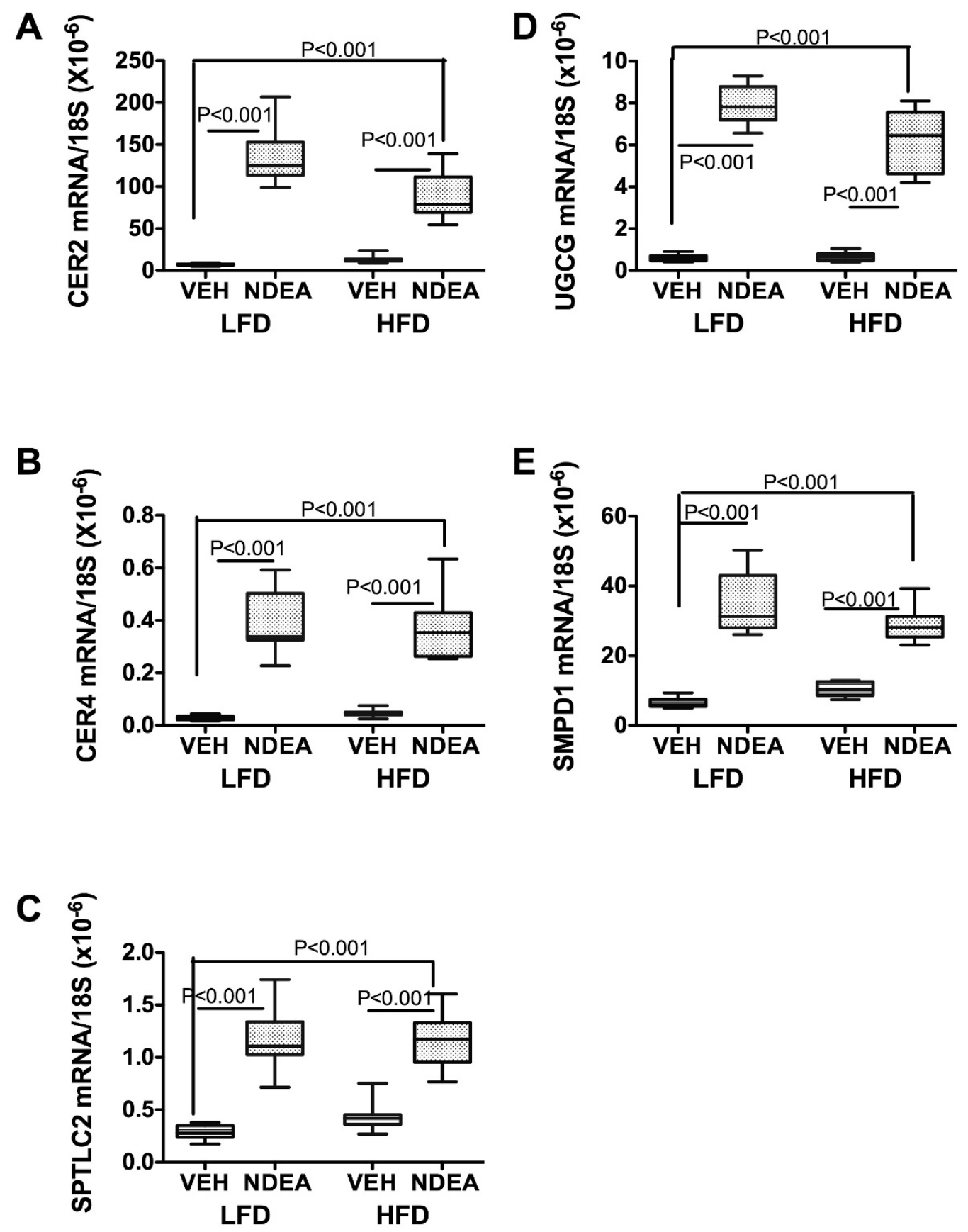

Figure 8

Effect of NDEA exposure and chronic HFD feeding on pro-ceramide gene expression in liver. Long Evans rats treated with NDEA or vehicle (VEH) by i.p. injection ( $\mathrm{N}=8$ /group), and then chronically fed with high fat (HFD) or low fat (LFD) containing chow for 6 weeks (see Figure Legend I). Total RNA extracted from liver tissue was reverse transcribed using random oligodeoxynucleotide primers, and the resulting CDNA templates were used in qRT-PCR assays to measure (A) Ceramide synthase (CER) 2, (B) CER4, (C) Serine palmitoyltransferase 2 (SPTLC2), (D) UDP-glucose ceramide glycoysltransferase (UGCG), or (E) sphingomyelin phosphodiesterase I (SMPDI). The mRNA levels were normalized to I8S rRNA measured in the same templates. Graphs depict the mean \pm S.E.M. levels of gene expression. Inter-group comparisons were made using ANOVA with the post-hoc Bonferroni test of significance. Significant P-values are indicated within the panels. 
Table 5: Effects of High Fat Diet and NDEA Exposure on Expression of Pro-Ceramide Genes in Temporal Lobe

\begin{tabular}{|c|c|c|c|c|c|c|}
\hline & LFD & LFD+NDEA & HFD & HFD+NDEA & F-Ratio & P-Value \\
\hline \multirow[t]{2}{*}{ CERI } & 6.710 & 6.055 & 6.794 & 7.381 & & \\
\hline & 0.651 & 0.685 & 0.984 & 0.996 & & \\
\hline \multirow[t]{2}{*}{ CER2 } & 19.230 & $4.858 * * *$ & 16.260 & $4.733^{* *}$ & 18.780 & $<0.0001$ \\
\hline & 2.017 & 0.752 & 2.509 & 0.495 & & \\
\hline \multirow[t]{2}{*}{ CER4 } & 2.352 & $3.620 *$ & 2.770 & $4.608^{* * *}$ & 11.030 & $<0.0001$ \\
\hline & 0.139 & 0.147 & 0.249 & 0.495 & & \\
\hline \multirow[t]{2}{*}{ CER5 } & 18.370 & $4.898 * * *$ & 21.120 & $5.277^{* * * *}$ & 18.540 & $<0.0001$ \\
\hline & 2.517 & 0.295 & 2.707 & 0.576 & & \\
\hline \multirow[t]{2}{*}{ UGCG } & 13.670 & $29.960 * * *$ & 15.190 & $30.590 * * *$ & 15.330 & $<0.0001$ \\
\hline & 0.929 & 3.605 & 1.667 & 2.827 & & \\
\hline \multirow[t]{2}{*}{ SMPDI } & 7.941 & 9.797 & $15.520 * * *$ & 9.490 & 6.919 & 0.001 \\
\hline & 0.766 & 1.435 & I.84| & 0.859 & & \\
\hline \multirow[t]{2}{*}{ SMPD3 } & 4.405 & $28.910 * * *$ & 2.672 & $16.170 * *$ & 21.170 & $<0.0001$ \\
\hline & 0.396 & 5.078 & 0.325 & 0.603 & & \\
\hline \multirow[t]{2}{*}{ SPTLCI } & 0.066 & $0.038^{*}$ & $0.029 * *$ & $0.042^{*}$ & 5.102 & 0.005 \\
\hline & 0.010 & 0.008 & 0.004 & 0.006 & & \\
\hline \multirow[t]{2}{*}{ SPTLC2 } & 1.728 & $1.107^{*}$ & 1.939 & 1.646 & 3.845 & 0.019 \\
\hline & 0.190 & 0.207 & 0.173 & 0.115 & & \\
\hline
\end{tabular}

Gene expression was measured by qRT-PCR with results normalized to I8S rRNA (see Methods). Values correspond to mRNA/I8S $\times 10^{-6}$. Intergroup comparisons were made using ANOVA tests. For all measurements, $\mathrm{df}=3 / 36$. Significant differences relative to the LFD control group were demonstrated using the Dunnett's post-hoc multiple comparison test (*P $<0.05$; **P $<0.01$; ***P $<0.00 \mathrm{I})$.

The mechanisms of sustained brain and liver insulin- and IGF-1 resistance in the context of NDEA exposure \pm HFD feeding are not well understood. The fact that NDEA \pm HFD feeding caused NASH, led us to investigate whether toxic lipids stemming from NASH-related injury could contribute to NDEA-mediated neurodegeneration. Since pro-ceramide genes are increased in experimental models of NASH $[68,71,74,91]$, and ceramides cause neurodegeneration, pro-inflammatory cytokine activation, and insulin resistance $[4,38,68,71-74,92,93]$, we measured mRNA levels of pro-ceramide genes in liver and brain. Those studies revealed strikingly increased levels of several genes involved in ceramide generation via both biosynthesis and degradation pathways in livers of NDEA-treated rats, with virtually no additional impact of HFD feeding. Since both NDEA and ceramides are lipid soluble $[94,95]$, and therefore likely to readily cross the blood-brain barrier, NDEA exposure could cause CNS insulin resistance and chronic injury by dual mechanisms: 1) direct neurotoxic injury with locally increased production of adducts and pro-ceramide gene expression; and 2) increased hepatic ceramide synthesis leading to the establishment of a liverbrain axis of neurodegeneration. Correspondingly, the qRT-PCR results suggest that hepatic-origin ceramide is generated by both synthetic and degradative pathways in NDEA-treated rats, whereas in the brain, ceramide gene expression was strikingly increased via degradative pathway mechanisms, and inhibited via the synthetic pathways. Preliminary studies suggest that in vivo intraperitoneal administration of toxic ceramides is sufficient to cause brain insulin resistance, neurodegeneration, and cognitive impairment (Tong, et al, unpublished).

\section{Conclusions}

We demonstrated that limited, low-level exposure to submutagenic doses of NDEA, together with chronic HFD feeding, act additively in causing peripheral, hepatic and brain insulin and IGF-1 resistance associated with T2DM, NAFLD/NASH, and neurodegeneration. The neurodegeneration had features in common with $\mathrm{AD}$, including impairments in learning and memory, cholinergic function, and neuronal cytoskeletal gene and protein expression. These abnormalities were associated with increased pro-ceramide gene expression, and since ceramides promote insulin resistance, neuro-inflammation, and neurodegeneration, characterization and measurement of ceramides and related lipotoxins in blood may prove useful as biomarkers of insulin-resistance disease progression toward T2DM, NASH, or AD. The molecular and biochemical abnormalities detected are quite reminiscent of the findings in the ic-STZ model [51]. Altogether, these results raise concerns about the double insult of chronic, low-level nitrosamine exposure and high dietary fat consumption as major mediators of our insulin resistance disease epidemic.

\section{Abbreviations}

A $\beta$ PP: amyloid- $\beta$-precursor protein; A $\beta P P-A \beta$ : amyloid- $\beta$ peptide; AChE: acetylcholinesterase; $\mathrm{AD}$ : Alzheimer's disease; CER: Ceramide synthase; ChAT: choline acetyltransferase; ELISA: enzyme-linked immunosorbant assay; GFAP: glial fibrillary acidic protein; GSK-3 $\beta$-glycogen synthase kinase-3 $\beta$; H\&E: hematoxylin and eosin; HFD: high fat diet; HNE: 4-hydroxy-2-nonenal; HRP: horseradish peroxidase; i.p.: intraperitoneal; IGF: Insulin like growth 
factor; IRS: Insulin receptor substrate; LFD: low fat diet; LHE: Luxol fast blue hematoxylin and eosin; MCI: mild cognitive impairment; NASH: non-alcoholic steatohepatitis; NDEA: N-nitrosodiethylamine; NDMA: Nnitrosodimethylamine; P3: postnatal day 3; qRT-PCR: quantitative reverse transcriptase polymerase chain reaction; SMPD: sphingomyelin phosphodiesterase; SPTLC: Serine palmitoyltransferase; STZ: Streptozotocin; T2DM: Type 2 diabetes mellitus; TBS: Tris buffered saline; UGCG: UDP-glucose ceramide glycoysltransferase.

\section{Competing interests}

The authors declare that they have no competing interests.

\section{Authors' contributions}

All authors have read and approved of the final manuscript. Ming Tong generated the model, harvested and processed tissue for histopathologic, molecular, and biochemical assays, performed qRT-PCR, ELISA, and immunostaining studies, analyzed data, reviewed manuscript. Lisa Longato and Margot Lawton performed serum assays, ELISAs, and qRT-PCR assays, analyzed data, reviewed manuscript Suzanne de la Monte-generated hypothesis, designed experiments, supervised work and data analysis, interpreted results, wrote manuscript.

\section{Acknowledgements}

Supported by AA-02666, AA-02169, AA-II43I, AA-12908, and K24-AA16126 from the National Institutes of Health

\section{References}

I. Rector RS, Thyfault JP, Wei Y, Ibdah JA: Non-alcoholic fatty liver disease and the metabolic syndrome: an update. World J Gastroenterol 2008, I 4(2): 185-192.

2. Pradhan A: Obesity, metabolic syndrome, and type 2 diabetes: inflammatory basis of glucose metabolic disorders. Nutr Rev 2007, 65( (12 Pt 2):SI52-156.

3. Launer LJ: Next steps in Alzheimer's disease research: interaction between epidemiology and basic science. Curr Alzheimer Res 2007, 4(2): 14I-I43.

4. Wang G, Silva J, Dasgupta S, Bieberich E: Long-chain ceramide is elevated in presenilin I (PSIMI46V) mouse brain and induces apoptosis in PSI astrocytes. Glia 2008, 56(4):449-456.

5. Delgado JS: Evolving trends in nonalcoholic fatty liver disease. Eur J Intern Med 2008, 19(2):75-82.

6. Nugent $C$, Younossi ZM: Evaluation and management of obesity-related nonalcoholic fatty liver disease. Nat Clin Pract Gastroenterol Hepatol 2007, 4(8):432-44I.

7. de la Monte SM, Neusner A, Chu J, Lawton M: Epidemilogical Trends Strongly Suggest Exposures as Etiologic Agents in the Pathogenesis of Sporadic Alzheimer's Disease, Diabetes Mellitus, and Non-Alcoholic Steatohepatitis. J Alzheimers Dis 2009, I 7(3):519-529.

8. Swann PF, Magee PN: Nitrosamine-induced carcinogenesis. The alklylation of nucleic acids of the rat by $\mathrm{N}$-methyl-Nnitrosourea, dimethylnitrosamine, dimethyl sulphate and methyl methanesulphonate. Biochem J 1968, I I 0(I):39-47.

9. Espey MG, Miranda KM, Thomas DD, Xavier S, Citrin D, Vitek MP, Wink DA: A chemical perspective on the interplay between NO, reactive oxygen species, and reactive nitrogen oxide species. Ann N Y Acad Sci 2002, 962:195-206.

10. Pasquier F, Boulogne A, Leys D, Fontaine P: Diabetes mellitus and dementia. Diabetes Metab 2006, 32(5 Pt I):403-4I4.
II. Nicolls MR: The clinical and biological relationship between Type II diabetes mellitus and Alzheimer's disease. Curr Alzheimer Res 2004, I (I):47-54.

12. Yeh MM, Brunt EM: Pathology of nonalcoholic fatty liver disease. Am J Clin Pathol 2007, I 28(5):837-847.

13. Marchesini G, Marzocchi R: Metabolic syndrome and NASH. Clin Liver Dis 2007, I I ( ): I05- I I7. ix

14. Papandreou D, Rousso I, Mavromichalis I: Update on non-alcoholic fatty liver disease in children. Clin Nutr 2007, 26(4):409-4I5.

15. Pessayre $D$ : Role of mitochondria in non-alcoholic fatty liver disease. J Gastroenterol Hepatol 2007, 22(SuppI I):S20-27.

16. Wei Y, Rector RS, Thyfault JP, Ibdah JA: Nonalcoholic fatty liver disease and mitochondrial dysfunction. World J Gastroenterol 2008, I4(2):193-199.

17. Bolzan AD, Bianchi MS: Genotoxicity of streptozotocin. Mutat Res 2002, 5 I 2(2-3): 12।-134.

18. Rossini AA, Like AA, Chick WL, Appel MC, Cahill GF Jr: Studies of streptozotocin-induced insulitis and diabetes. Proc Natl Acad Sci USA 1977, 74(6):2485-2489.

19. Szkudelski T: The mechanism of alloxan and streptozotocin action in B cells of the rat pancreas. Physiol Res 200I, 50(6):537-546.

20. Doi K: [Studies on the mechanism of the diabetogenic activity of streptozotocin and on the ability of compounds to block the diabetogenic activity of streptozotocin (author's transl)]. Nippon Naibunpi Gakkai Zasshi 1975, 5 I (3): I 29- 147.

21. Iwai S, Murai T, Makino S, Min W, Morimura K, Mori S, Hagihara A, Seki S, Fukushima S: High sensitivity of fatty liver Shionogi (FLS) mice to diethylnitrosamine hepatocarcinogenesis: comparison to C3H and C57 mice. Cancer Lett 2007, 246(I2): $|15-12|$.

22. de la Monte SM, Tong M, Lester-Coll N, Plater M Jr, Wands JR: Therapeutic rescue of neurodegeneration in experimental type 3 diabetes: relevance to Alzheimer's disease. J Alzheimers Dis 2006, I0(I):89-109.

23. Hoyer S: Causes and consequences of disturbances of cerebral glucose metabolism in sporadic Alzheimer disease: therapeutic implications. Adv Exp Med Biol 2004, 54 I:I35-I52.

24. Hoyer S, Lannert H, Noldner M, Chatterjee SS: Damaged neuronal energy metabolism and behavior are improved by Ginkgo biloba extract (EGb 76I). J Neural Transm 1999, I06(III2): I I7I-II88.

25. Lester-Coll N, Rivera EJ, Soscia SJ, Doiron K, Wands JR, de la Monte SM: Intracerebral streptozotocin model of type 3 diabetes: relevance to sporadic Alzheimer's disease. J Alzheimers Dis 2006, 9(I): 13-33.

26. Murata M, Takahashi A, Saito I, Kawanishi S: Site-specific DNA methylation and apoptosis: induction by diabetogenic streptozotocin. Biochem Pharmacol 1999, 57(8):88I-887.

27. Nukatsuka $M$, Sakurai $H$, Yoshimura $Y$, Nishida M, Kawada J: Enhancement by streptozotocin of O2- radical generation by the xanthine oxidase system of pancreatic beta-cells. FEBS Lett 1988, 239(2):295-298.

28. West IC: Radicals and oxidative stress in diabetes. Diabet Med 2000, I7(3): $17 \mid-180$

29. Robbiano L, Mereto E, Corbu C, Brambilla G: DNA damage induced by seven $\mathbf{N}$-nitroso compounds in primary cultures of human and rat kidney cells. Mutat Res 1996, 368(I):4I-47.

30. Verdelho A, Madureira S, Ferro JM, Basile AM, Chabriat H, Erkinjuntti T, Fazekas F, Hennerici M, O'Brien J, Pantoni L, Salvadori E, Scheltens P, Visser MC, Wahlund LO, Waldemar G, Wallin A, Inzitari D: Differential impact of cerebral white matter changes, diabetes, hypertension and stroke on cognitive performance among non-disabled elderly. The LADIS study. J Neurol Neurosurg Psychiatry 2007, 78(12): 1325-1330.

3I. Martins IJ, Hone E, Foster JK, Sunram-Lea SI, Gnjec A, Fuller SJ, Nolan D, Gandy SE, Martins RN: Apolipoprotein E, cholesterol metabolism, diabetes, and the convergence of risk factors for Alzheimer's disease and cardiovascular disease. Mol Psychiatry 2006, II (8):72I-736.

32. Craft S: Insulin resistance syndrome and Alzheimer disease: pathophysiologic mechanisms and therapeutic implications. Alzheimer Dis Assoc Disord 2006, 20(4):298-30I. 
33. Craft S: Insulin resistance and Alzheimer's disease pathogenesis: potential mechanisms and implications for treatment. Curr Alzheimer Res 2007, 4(2): | 47-I 52.

34. Rivera EJ, Goldin A, Fulmer N, Tavares R, Wands JR, de la Monte SM: Insulin and insulin-like growth factor expression and function deteriorate with progression of Alzheimer's disease: link to brain reductions in acetylcholine. J Alzheimers Dis 2005 , 8(3):247-268.

35. Steen E, Terry BM, Rivera EJ, Cannon JL, Neely TR, Tavares R, Xu XJ, Wands JR, de la Monte SM: Impaired insulin and insulin-like growth factor expression and signaling mechanisms in Alzheimer's disease--is this type 3 diabetes? J Alzheimers Dis 2005, 7(I):63-80.

36. Winocur G, Greenwood CE: Studies of the effects of high fat diets on cognitive function in a rat model. Neurobiol Aging 2005, 26(Suppl I):46-49.

37. Winocur G, Greenwood CE, Piroli GG, Grillo CA, Reznikov LR, Reagan LP, McEwen BS: Memory impairment in obese Zucker rats: an investigation of cognitive function in an animal model of insulin resistance and obesity. Behav Neurosci 2005, I | 9(5): I 389-I395.

38. Lyn-Cook LE Jr, Lawton M, Tong M, Silbermann E, Longato L, Jiao P, Mark P, Wands JR, Xu H, de la Monte SM: Hepatic Ceramide May Mediate Brain Insulin Resistance and Neurodegeneration in Type 2 Diabetes and Non-alcoholic Steatohepatitis. J Alzheimers Dis 2009, I 6(4):715-729.

39. Moroz N, Tong M, Longato L, Xu H, de la Monte SM: Limited Alzheimer-type neurodegeneration in experimental obesity and type 2 diabetes mellitus. J Alzheimers Dis 2008, I 5(I):29-44.

40. Biju MP, Paulose CS: Brain glutamate dehydrogenase changes in streptozotocin diabetic rats as a function of age. Biochem Mol Biol Int 1998, 44(I): I-7.

4I. Nitta A, Murai R, Suzuki N, Ito H, Nomoto H, Katoh G, Furukawa Y, Furukawa S: Diabetic neuropathies in brain are induced by deficiency of BDNF. Neurotoxicol Teratol 2002, 24(5):695-70I.

42. Weinstock $M$, Shoham S: Rat models of dementia based on reductions in regional glucose metabolism, cerebral blood flow and cytochrome oxidase activity. J Neural Transm 2004, I I I (3):347-366

43. Haan MN: Therapy Insight: type 2 diabetes mellitus and the risk of late-onset Alzheimer's disease. Nat Clin Pract Neurol 2006, 2(3): 159-166.

44. Landreth G: Therapeutic use of agonists of the nuclear receptor PPARgamma in Alzheimer's disease. Curr Alzheimer Res 2007, 4(2): 159-164.

45. Pedersen WA, McMillan PJ, Kulstad JJ, Leverenz JB, Craft S, Haynatzki GR: Rosiglitazone attenuates learning and memory deficits in Tg2576 Alzheimer mice. Exp Neurol 2006, I99(2):265-273.

46. Reger MA, Craft S: Intranasal insulin administration: a method for dissociating central and peripheral effects of insulin. Drugs Today (Barc) 2006, 42(I I):729-739.

47. Reger MA, Watson GS, Frey WH, Baker LD, Cholerton B, Keeling ML, Belongia DA, Fishel MA, Plymate SR, Schellenberg GD, Cherrier $M M$, Craft $S$ : Effects of intranasal insulin on cognition in memory-impaired older adults: modulation by APOE genotype. Neurobiol Aging 2006, 27(3):45 I-458.

48. Reger MA, Watson GS, Green PS, Wilkinson CW, Baker LD, Cholerton B, Fishel MA, Plymate SR, Breitner JC, Degroodt W, Mehta P, Craft S: Intranasal insulin improves cognition and modulates \{beta\}-amyloid in early AD. Neurology 2008, 70(6):440-448.

49. Watson GS, Bernhardt T, Reger MA, Cholerton BA, Baker LD, Peskind ER, Asthana S, Plymate SR, Frolich L, Craft S: Insulin effects on CSF norepinephrine and cognition in Alzheimer's disease. Neurobiol Aging 2006, 27(I):38-4I.

50. Penberthy WT: Pharmacological targeting of IDO-mediated tolerance for treating autoimmune disease. Curr Drug Metab 2007, 8(3):245-266.

51. de la Monte SM, Wands JR: Alzheimer's Disease is Type 3 Diabetes: Evidence Reviewed. J Diabetes Science Tech 2008, 2(6): I I0I-III3.

52. Butler SM, Ashford JW, Snowdon DA: Age, education, and changes in the Mini-Mental State Exam scores of older women: findings from the Nun Study. J Am Geriatr Soc 1996, 44(6):675-68I.

53. Snowdon DA, Kemper SJ, Mortimer JA, Greiner LH, Wekstein DR, Markesbery WR: Linguistic ability in early life and cognitive function and Alzheimer's disease in late life. Findings from the Nun Study. JAMA 1996, 275(7):528-532.

54. de la Monte SM, Wands JR: Review of insulin and insulin-like growth factor expression, signaling, and malfunction in the central nervous system: relevance to Alzheimer's disease. J Alzheimers Dis 2005, 7(I):45-6I.

55. Hickey RW, Akino M, Strausbaugh S, De Courten-Myers GM: Use of the Morris water maze and acoustic startle chamber to evaluate neurologic injury after asphyxial arrest in rats. Pediatr Res 1996, 39(I):77-84.

56. Fowler SD, Greenspan P: Application of Nile red, a fluorescent hydrophobic probe, for the detection of neutral lipid deposits in tissue sections: comparison with oil red $\mathbf{O}$. J Histochem Cytochem 1985, 33(8):833-836

57. Greenspan P, Fowler SD: Spectrofluorometric studies of the lipid probe, nile red. J Lipid Res 1985, 26(7):781-789.

58. McMillian MK, Grant ER, Zhong Z, Parker JB, Li L, Zivin RA, Burczynski ME, Johnson MD: Nile Red binding to HepG2 cells: an improved assay for in vitro studies of hepatosteatosis. In Vitr Mol Toxicol 200I, I4(3): I77-190.

59. Tong M, Neusner A, Longato L, Lawton M, Wands JR, de la Monte $S M$ : Nitrosamine exposure causes insulin resistance diseases: Relevance to type 2 diabetes mellitus, non-alcoholic steatohepatitis, and Alzheimer's disease in humans. J Alz Dis 2009 in press.

60. Cohen AC, Tong M, Wands JR, de la Monte SM: Insulin and insulinlike growth factor resistance with neurodegeneration in an adult chronic ethanol exposure model. Alcohol Clin Exp Res 2007, 3 I (9): | $558-1573$

61. Soscia SJ, Tong M, Xu XJ, Cohen AC, Chu J, Wands JR, de la Monte SM: Chronic gestational exposure to ethanol causes insulin and IGF resistance and impairs acetylcholine homeostasis in the brain. Cell Mol Life Sci 2006, 63(I 7):2039-2056.

62. Hietanen E, Bartsch H, Ahotupa M, Bereziat JC, Bussacchini-Griot V Cabral JR, Camus AM, Laitinen M, Wild H: Mechanisms of fatrelated modulation of $\mathbf{N}$-nitrosodiethylamine-induced tumors in rats: organ distribution, blood lipids, enzymes and pro-oxidant state. Carcinogenesis I99I, I 2(4):59I-600.

63. Cong WN, Tao RY, Tian JY, Liu GT, Ye F: The establishment of a novel non-alcoholic steatohepatitis model accompanied with obesity and insulin resistance in mice. Life Sci 2008, 82(19-20):983-990.

64. Kirsch R, Clarkson V, Verdonk RC, Marais AD, Shephard EG, Ryffel $B$, de la MHP: Rodent nutritional model of steatohepatitis: effects of endotoxin (lipopolysaccharide) and tumor necrosis factor alpha deficiency. J Gastroenterol Hepatol 2006, 2 I (I Pt I): $174-182$

65. Yoshimatsu M, Terasaki Y, Sakashita N, Kiyota E, Sato H, Laan LJ van der, Takeya $M$ : Induction of macrophage scavenger receptor MARCO in nonalcoholic steatohepatitis indicates possible involvement of endotoxin in its pathogenic process. Int J Exp Pathol 2004, 85(6):335-343.

66. Sakhuja P, Malhotra V: Nonalcoholic steatohepatitis--a histological perspective. Indian J Pathol Microbiol 2006, 49(2): I63-I72.

67. Steen B: Maximizing outcome of dementia treatment: the role of nutrition. Arch Gerontol Geriatr Suppl 2004:4I3-4I7.

68. Alessenko AV, Bugrova AE, Dudnik LB: Connection of lipid peroxide oxidation with the sphingomyelin pathway in the development of Alzheimer's disease. Biochem Soc Trans 2004, 32(Pt I): | $44-146$

69. Laviad EL, Albee L, Pankova-Kholmyansky I, Epstein S, Park H, Merrill $\mathrm{AH}$ Jr, Futerman $\mathrm{AH}$ : Characterization of ceramide synthase 2: tissue distribution, substrate specificity, and inhibition by sphingosine I-phosphate. J Biol Chem 2008, 283(9):5677-5684.

70. Shah C, Yang G, Lee I, Bielawski J, Hannun YA, Samad F: Protection from high fat diet-induced increase in ceramide in mice lacking plasminogen activator inhibitor I. J Biol Chem 2008, 283(20): I 3538-| 3548 .

7I. Summers SA: Ceramides in insulin resistance and lipotoxicity. Prog Lipid Res 2006, 45(I):42-72.

72. Tong $M$, de la Monte SM: Mechanisms of ceramide-mediated neurodegeneration. J Alzheimers Dis 2009, I6(4):705-7|4.

73. Adibhatla RM, Hatcher JF: Altered Lipid Metabolism in Brain Injury and Disorders. Subcell Biochem 2008, 48:. nihpa4I04I

74. Katsel P, Li C, Haroutunian V: Gene expression alterations in the sphingolipid metabolism pathways during progression of 
dementia and Alzheimer's disease: a shift toward ceramide accumulation at the earliest recognizable stages of Alzheimer's disease? Neurochem Res 2007, 32(4-5):845-856.

75. Nakane M, Kubota M, Nakagomi T, Tamura A, Hisaki H, Shimasaki H, Ueta $\mathrm{N}$ : Lethal forebrain ischemia stimulates sphingomyelin hydrolysis and ceramide generation in the gerbil hippocampus. Neurosci Lett 2000, 296(2-3):89-92.

76. Weiland D, Mondon CE, Reaven GM: Evidence for multiple causality in the development of diabetic hypertriglyceridaemia. Diabetologia 1980, 18(4):335-340.

77. Wang XP, Ding HL: Alzheimer's disease: epidemiology, genetics, and beyond. Neurosci Bull 2008, 24(2): 105-109.

78. Lijinsky W, Reuber MD, Riggs CW: Dose response studies of carcinogenesis in rats by nitrosodiethylamine. Cancer Res 198I, 4 I ( I 2 Pt I):4997-5003.

79. Lijinsky W, Saavedra JE, Reuber MD: Induction of carcinogenesis in Fischer rats by methylalkylnitrosamines. Cancer Res 198I, 4I(4): I 288-I 292.

80. Bansal AK, Bansal M, Soni G, Bhatnagar D: Protective role of Vitamin $\mathrm{E}$ pre-treatment on $\mathbf{N}$-nitrosodiethylamine induced oxidative stress in rat liver. Chem Biol Interact 2005, I56(23): I0I-III.

81. Clapp NK, Craig AW, Toya RE Sr: Diethylnitrosamine oncogenesis in RF mice as influenced by variations in cumulative dose. Int J Cancer 1970, 5( I): I19-123.

82. Siegmund KD, Connor CM, Campan M, Long TI, Weisenberger DJ, Biniszkiewicz D, Jaenisch R, Laird PW, Akbarian S: DNA methylation in the human cerebral cortex is dynamically regulated throughout the life span and involves differentiated neurons. PLoS One 2007, 2(9):e895.

83. Budovsky A, Muradian KK, Fraifeld VE: From disease-oriented to aging/longevity-oriented studies. Rejuvenation Res 2006, 9(2):207-210.

84. Goldman R, Shields PG: Food mutagens. J Nutr 2003, I33(Suppl 3):965S-973S.

85. Liu WB, Liu JY, Ao L, Zhou ZY, Zhou YH, Cui ZH, Yang H, Cao J: Dynamic changes in DNA methylation during multistep rat lung carcinogenesis induced by 3-methylcholanthrene and diethylnitrosamine. Toxicol Lett 2009, 189(I):5-13.

86. lizuka $S$, Suzuki $W$, Tabuchi M, Nagata M, Imamura $S$, Kobayashi $Y$, Kanitani M, Yanagisawa T, Kase Y, Takeda S, Aburada M, Takahashi KW: Diabetic complications in a new animal model (TSOD mouse) of spontaneous NIDDM with obesity. Exp Anim 2005, 54(I):7I-83.

87. Figueroa CD, Taberner PV: Pancreatic islet hypertrophy in spontaneous maturity onset obese-diabetic CBA/Ca mice. Int J Biochem 1994, 26 (I 0-1 I): I 299-1303.

88. Myers SR, Ali MY: Haemoglobin adducts as biomarkers of exposure to tobacco-related nitrosamines. Biomarkers 2008, I3(2): 145-159.

89. Chen GJ, Xu J, Lahousse SA, Caggiano NL, de la Monte SM: Transient hypoxia causes Alzheimer-type molecular and biochemical abnormalities in cortical neurons: potential strategies for neuroprotection. J Alzheimers Dis 2003, 5(3):209-228.

90. Inokuchi J: Insulin resistance as a membrane microdomain disorder. Yakugaku Zasshi 2007, I 27(4):579-586.

91. Han MS, Park SY, Shinzawa K, Kim S, Chung KW, Lee JH, Kwon CH, Lee KW, Park CK, Chung WJ, Hwang JS, Yan JJ, Song DK, Tsujimoto $Y$, Lee MS: Lysophosphatidylcholine as a death effector in the lipoapoptosis of hepatocytes. J Lipid Res 2008, 49(I):84-97.

92. Holland WL, Knotts TA, Chavez JA, Wang LP, Hoehn KL, Summers SA: Lipid mediators of insulin resistance. Nutr Rev 2007, 65(6 Pt 2):S39-46.

93. Kraegen EW, Cooney GJ: Free fatty acids and skeletal muscle insulin resistance. Curr Opin Lipidol 2008, 19(3):235-24I.

94. Pylypiw HM, Zubroff JR, Magee PN, Harrington GW: The metabolism of N-nitrosomethylaniline. J Cancer Res Clin Oncol 1984, 108(I):66-70.

95. Singer GM, Taylor HW, Lijinsky W: Liposolubility as an aspect of nitrosamine carcinogenicity: quantitative correlations and qualitative observations. Chem Biol Interact 1977, 19(2): 133-142.
Publish with Bio Med Central and every scientist can read your work free of charge

"BioMed Central will be the most significant development for disseminating the results of biomedical research in our lifetime. "

Sir Paul Nurse, Cancer Research UK

Your research papers will be:

- available free of charge to the entire biomedical community

- peer reviewed and published immediately upon acceptance

- cited in PubMed and archived on PubMed Central

- yours - you keep the copyright

Submit your manuscript here:

http://www.biomedcentral.com/info/publishing_adv.asp
BioMedcentral 